\title{
The instrument constant of sky radiometers (POM-02) - Part 1: Calibration constant
}

\author{
Akihiro Uchiyama $^{1}$, Tsuneo Matsunaga ${ }^{1}$, and Akihiro Yamazaki ${ }^{2}$ \\ ${ }^{1}$ Center for Global Environmental Research, National Institute for Environmental Studies, Tsukuba, Ibaraki 305-8506, Japan \\ ${ }^{2}$ Meteorological Research Institute, Japan Meteorological Agency, Tsukuba, Ibaraki 305-0052, Japan
}

Correspondence: Akihiro Uchiyama (uchiyama.akihiro@nies.go.jp)

Received: 30 November 2017 - Discussion started: 11 January 2018

Revised: 11 January 2018 - Accepted: 13 August 2018 - Published: 26 September 2018

\begin{abstract}
Ground-based networks have been developed to determine the spatiotemporal distribution of the optical properties of aerosols using radiometers. In this study, the precision of the calibration constant $\left(V_{0}\right)$ for the sky radiometer (POM-02) that is used by SKYNET was investigated. The temperature dependence of the sensor output was also investigated, and the dependence in the 340,380 , and $2200 \mathrm{~nm}$ channels was found to be larger than for other channels and varied with the instrument. In the summer, the sensor output had to be corrected by a factor of $1.5 \%$ to $2 \%$ in the 340 and $380 \mathrm{~nm}$ channels and by $4 \%$ in the $2200 \mathrm{~nm}$ channel in the measurements at Tsukuba $\left(36.05^{\circ} \mathrm{N}, 140.13^{\circ} \mathrm{E}\right)$, with a monthly mean temperature range of 2.7 to $25.5^{\circ} \mathrm{C}$. In the other channels, the correction factors were less than $0.5 \%$. The coefficient of variation (CV, standard deviation/mean) of $V_{0}$ from the normal Langley method, based on the data measured at the NOAA Mauna Loa Observatory, is between $0.2 \%$ and $1.3 \%$, except in the $940 \mathrm{~nm}$ channel. The effect of gas absorption was less than $1 \%$ in the 1225,1627 , and $2200 \mathrm{~nm}$ channels. The degradation of $V_{0}$ for wavelengths shorter than $400 \mathrm{~nm}(-10 \%$ to $-4 \%$ per year) was larger than that for wavelengths longer than $500 \mathrm{~nm}(-1$ to nearly $0 \%$ per year). The $\mathrm{CV}$ of $V_{0}$ transferred from the reference POM-02 was $0.1 \%$ to $0.5 \%$. Here, the data were simultaneously taken at $1 \mathrm{~min}$ intervals on a fine day, and data when the air mass was less than 2.5 were compared. The $V_{0}$ determined by the improved Langley (IML) method had a seasonal variation of $1 \%$ to $3 \%$. The root mean square error (RMSE) from the IML method was about $0.6 \%$ to $2.5 \%$, and in some cases the maximum difference reached $5 \%$. The trend in $V_{0}$ after removing the seasonal variation was almost the same as for the normal Langley method. Furthermore,
\end{abstract}

the calibration constants determined by the IML method had much higher noise than those transferred from the reference. The modified Langley method was used to calibrate the $940 \mathrm{~nm}$ channel with on-site measurement data. The $V_{0}$ obtained with the modified Langley method compared to the Langley method was $1 \%$ more accurate on stable and fine days. The general method was also used to calibrate the shortwave-infrared channels $(1225,1627$, and $2200 \mathrm{~nm})$ with on-site measurement data; the $V_{0}$ obtained with the general method differed from that obtained with the Langley method of $V_{0}$ by $0.8 \%, 0.4 \%$, and $0.1 \%$ in December 2015, respectively.

\section{Introduction}

Atmospheric aerosols are an important constituent of the atmosphere. Aerosols change the radiation budget directly by absorbing and scattering solar radiation and indirectly through their role as cloud condensation nuclei (CCNs), thereby increasing cloud reflectivity and lifetime (e.g., Ramanathan et al., 2001; Lohmann and Feichter, 2005). As one of the main components of air pollution, aerosols also affect human health (Dockery et al., 1993; WHO, 2006, 2013).

Atmospheric aerosols have a large variability in time and space. Therefore, measurement networks covering an extensive area on the ground and from space have been developed and established to determine the spatiotemporal distribution of aerosols.

Ground-based observation systems, such as those using radiometers, are more reliable and easier to install and maintain than space-based systems. Therefore, ground-based ob- 
servation data are used to validate data obtained from spacebased systems (Kahn et al., 2005; Remer et al., 2005; Mélin et al., 2010). Well-known ground-based networks include AERONT (Aerosol Robotic Network) (Holben et al., 1998), SKYNET (Takamura et al., 2004), and GAW-PFR (Global Atmosphere Watch-Precision Filter Radiometer) (Wehrli, 2005).

In ground-based observation networks, direct solar irradiance and sky radiance are measured, and the column average effective aerosol characteristics are retrieved by analyzing these data: optical depth, single scattering albedo, phase function, complex refractive index, and size distribution. To improve the measurement accuracy, it is important to know the characteristics of the instruments and to calibrate the instruments. Furthermore, from the viewpoint of the validation of optical properties retrieved from the satellite measurement data, it is important to know the magnitude of the error in the ground-based measurements.

In SKYNET, the radiometers POM-01 and POM-02, manufactured by Prede Co. Ltd., Japan, are used. These radiometers are called "sky radiometers", and measure both the solar direct irradiance and sky-radiances (Takamura et al., 2004). The objectives in this study are to investigate the current status of and problems with the sky radiometer.

There are two constants that we must determine to make accurate measurements. One is the calibration constant, and the other is the solid view angle (SVA) of the radiometer. Following Nakajima et al. (1996), this paper uses the SVA to quantify the magnitude of the field of view (FOV). The calibration constant $V_{0}$ is the output of the radiometer to the extraterrestrial solar irradiance at the mean earth-sun distance (1 astronomical unit, AU) at the reference temperature. The SVA is a constant that relates the sensor output to the sky radiance. The ambient temperature affects the sensor output, and this temperature dependence must be considered when analyzing data from POM-01 and POM-02 (Prede, Japan). In this study, the temperature dependence of POM- 02 and the calibration of the sensor are described. The SVA is described in detail in Part 2 (Uchiyama et al., 2018).

In Sect. 2, we briefly describe the data used in this study. In Sect. 3, firstly, the temperature characteristics of POM-02 are described. Though the majority of POM-01 and POM-02 users do not explicitly consider the temperature dependence of the instruments, some channels have a large temperature dependence.

Secondly, the precision of the calibration constant is described. Most POM-01 and POM-02 users calibrate the sky radiometers with the improved Langley (IML) method (Tanaka et al., 1986; Campanelli et al., 2004), because this method only needs on-site measurement data and special measurements for calibration are not required. One of the goals of this paper is to examine the difference between the $V_{0}$ obtained by the IML method and by the normal Langley method, but before that, in Sect. 4, we briefly review the Langley method, and consider the precision of the normal Lan- gley method using the data obtained at the NOAA Mauna Loa Observatory (MLO), which is one of the most suitable places for sky radiometer calibration by the normal Langley method, and the precision of the calibration constant transfer obtained from side-by-side measurement. In Sect. 5, we briefly review the IML method, and though Campanelli et al. (2004) have already estimated the root mean square error (RMSE) of the IML method, we estimate it again and show the time variation and the relation between the calibration constant and temperature dependence. Then, in Sect. 6, an example of the precision of the calibration using a calibrated integrating sphere is shown.

In SKYNET, the 940, 1627, and $2200 \mathrm{~nm}$ channels were not used. Therefore, the precipitable water vapor (PWV) and the optical depth at $1627 \mathrm{~nm}$ are not estimated. However, these parameters are estimated in AERONET. In Sects. 7 and 8, calibration methods for these channels are shown using on-site measurement data. In Sect. 9, the results are summarized.

\section{Data}

In this study, measurements were conducted using two POM02 sky radiometers that are used by the Japan Meteorological Agency/Meteorological Research Institute (JMA/MRI). One is used as a calibration reference, POM-02 (calibration reference), and the other is used for continuous measurement at the Tsukuba MRI observation site, POM-02 (Tsukuba). In Table 1, the nominal specifications of the filters are shown. The JMA/MRI does not use the $315 \mathrm{~nm}$ channel because the transmittance of the lens was low at this wavelength. Instead, the JMA/MRI added a $1225 \mathrm{~nm}$ channel. The sensor output in the file storing the measurement values of POM-02 is the current: the unit is ampere (A). Therefore, the unit of the calibration constant in this paper is ampere (A).

To calibrate the reference POM-02 by the normal Langley method (i.e., the same air mass of air molecule scattering for all attenuating substances, see Sect. 4.1), the measurements were conducted at the NOAA Mauna Loa Observatory (MLO) for about one month every year, for more than 20 years. The MLO $\left(19.5362^{\circ} \mathrm{N}, 155.5763^{\circ} \mathrm{W}\right)$ is located at an elevation of $3397.0 \mathrm{~m}$ amsl on the northern slope of Mauna Loa, Island of Hawaii, Hawaii, USA. The atmospheric pressure is about $680 \mathrm{hPa}$. The MLO is one of the most suitable places to obtain data for a Langley plot (Shaw, 1983) and for a solar disk scan. Using these data, the calibration constant is estimated and the SVA is calculated.

The continuous observation was performed at the JMA/MRI $\left(36.05^{\circ} \mathrm{N}, 140.13^{\circ} \mathrm{E}\right)$ in Tsukuba, which is located about $50 \mathrm{~km}$ northeast of Tokyo. Using these continuous measurement data, the calibration constants for the IML method were calculated using the SKYRAD software package (Nakajima et al., 1996, OpenCLASTR, http://www.ccsr.u-tokyo.ac.jp/ clastr/, last 
Table 1. Nominal filter specification.

\begin{tabular}{lrrcccl}
\hline Channel no. & Wavelength $(\mathrm{nm})$ & FWHM $(\mathrm{nm})$ & Max. transmittance & Blocking & Blocking wavelength & Detector \\
\hline- & $315( \pm 0.6)^{\mathrm{a}}$ & $3.0( \pm 0.6)$ & $>30 \%$ & $1.0 \times 10^{-5}$ & $200-1200 \mathrm{~nm}$ & Si photodiode \\
1 & $340( \pm 0.6)$ & $3.0( \pm 0.6)$ & $>30 \%$ & $1.0 \times 10^{-5}$ & $200-1200 \mathrm{~nm}$ & Si photodiode \\
2 & $380( \pm 0.6)$ & $3.0( \pm 0.6)$ & $>30 \%$ & $1.0 \times 10^{-5}$ & $200-1200 \mathrm{~nm}$ & Si photodiode \\
3 & $400( \pm 0.6)$ & $10.0( \pm 2.0)$ & $>30 \%$ & $1.0 \times 10^{-5}$ & $200-1200 \mathrm{~nm}$ & Si photodiode \\
4 & $500( \pm 2.0)$ & $10.0( \pm 2.0)$ & $>30 \%$ & $1.0 \times 10^{-5}$ & $200-1200 \mathrm{~nm}$ & Si photodiode \\
5 & $675( \pm 2.0)$ & $10.0( \pm 2.0)$ & $>30 \%$ & $1.0 \times 10^{-5}$ & $200-1200 \mathrm{~nm}$ & Si photodiode \\
6 & $870( \pm 2.0)$ & $10.0( \pm 2.0)$ & $>30 \%$ & $1.0 \times 10^{-5}$ & $200-1200 \mathrm{~nm}$ Si photodiode \\
7 & $940( \pm 2.0)$ & $10.0( \pm 2.0)$ & $>30 \%$ & $1.0 \times 10^{-5}$ & $200-1200 \mathrm{~nm}$ Si photodiode \\
8 & $1020( \pm 2.0)$ & $10.0( \pm 2.0)$ & $>30 \%$ & $1.0 \times 10^{-5}$ & $200-3000 \mathrm{~nm}$ Si photodiode \\
9 & $1225( \pm 2.0)^{\mathrm{b}}$ & $20.0( \pm 2.0)$ & $>30 \%$ & $1.0 \times 10^{-5}$ & $600-3000 \mathrm{~nm}$ & InGaAs photodiode \\
10 & $1627( \pm 2.0)$ & $20.0( \pm 2.0)$ & $>30 \%$ & $1.0 \times 10^{-5}$ & $600-3000 \mathrm{~nm}$ & InGaAs photodiode \\
11 & $2200( \pm 2.0)$ & $20.0( \pm 2.0)$ & $>30 \%$ & $1.0 \times 10^{-5}$ & $600-3000 \mathrm{~nm}$ & InGaAs photodiode \\
\hline
\end{tabular}

FWHM: full width at half maximum. ${ }^{a} 315 \mathrm{~nm}$ channel is not used by JMA/MRI. ${ }^{\mathrm{b}} 1225 \mathrm{~nm}$ channel is used by JMA/ MRI.

access: 18 September 2018). Usually, the calibration of POM-02 for continuous measurement is conducted by comparison with the side-by-side measurement data from the reference POM-02.

The temperature dependence of the sensor output was measured using the same equipment that was originally used to measure the temperature dependence of the pyranometer. This equipment is managed and maintained by a branch of the JMA Observation Department. The main components of this equipment are a temperature-controlled chamber, light source, and stabilized power supply.

The measurements for investigating the temperature characteristics of POM-02 were made as follows.

To stabilize the equipment, the power supply of the equipment was turned on the day before the measurement date. On the measurement day, the light source was first turned on, then the temperature was varied every $90 \mathrm{~min}$, and the temperature and output from POM-02 were recorded continuously. The temperature was set to $40,20,0,-20,0,20$, 40 , and $20^{\circ} \mathrm{C}$. It took about 30 (40) min after increasing (decreasing) the temperature for the temperature and the output of POM-02 to become stable. Temperature characteristics were investigated using data between 70 and $90 \mathrm{~min}$ after varying the temperature.

To check the stability of the equipment, the staff of the JMA recorded the output of the pyranometer CMP-22 (Kipp $\&$ Zonen, Netherland) continuously for $11 \mathrm{~h}$ at a temperature setting of $20^{\circ} \mathrm{C}$. As a result, the variation of the hourly mean values of the output was within $\pm 0.05 \%$.

The temperature correction was performed for each individual measurement value. The temperature dependence of the sensor output was approximated by the following equation:

$V(T) / V\left(T=T_{\mathrm{r}}\right)=1.0+C_{1}\left(T-T_{\mathrm{r}}\right)+C_{2}\left(T-T_{\mathrm{r}}\right)^{2}$, where $V(T)$ is the sensor output at temperature $T, V(T=$ $\left.T_{\mathrm{r}}\right)$ is the sensor output at reference temperature $T_{\mathrm{r}}$, and coefficients $C_{1}$ and $C_{2}$ were determined by the least squares method. In the case of POM-02, the sensor output is current, and the unit is ampere (A). Therefore, the measured $V(T)$ is corrected using Eq. (1).

\section{Temperature dependence of sensor output}

In this section, the temperature characteristics of the POM-02 are described. The POM-02 is temperature-controlled; however, the temperature control is insufficient. Therefore, the sensor output of the POM-02 is dependent on the environmental temperature.

The purpose of the temperature control is to keep the temperature inside the instrument from decreasing to below levels that will reduce the instrument's precision. Instruments are designed to activate the heater when the inside temperature is less than 20 or $30^{\circ} \mathrm{C}$. For colder regions, such as polar regions, the minimum temperature threshold for activating the heater is $20^{\circ} \mathrm{C}$, and in other regions the threshold is $30^{\circ} \mathrm{C}$. When the temperature near the rotating filter wheel inside the instrument is below the threshold temperature (20 or $30^{\circ} \mathrm{C}$ ), the instrument is heated. When the temperature exceeds the threshold, heating is stopped. However, there is no cooling mechanism for when the temperature inside the instrument is higher than its threshold temperature. To monitor the temperature inside the instrument, a temperature sensor is attached near the rotating filter wheel. Furthermore, the shortwave-infrared detector, which is thermoelectrically cooled, is equipped with a temperature sensor and temperature data can be recorded.

In Fig. 1, an example of the relation between the temperature near the rotating filter wheel and the environmental temperature for POM-02 (calibration reference) is shown. The 


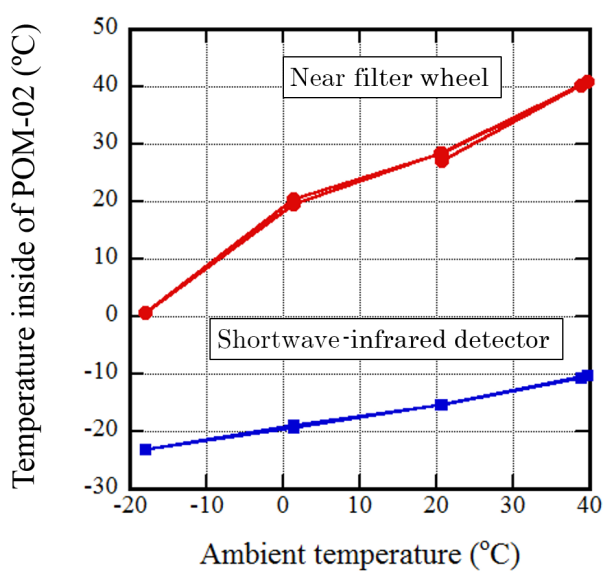

Figure 1. Relation between the inside temperatures of the instrument and the ambient environmental temperature for POM-02 (calibration reference).

red line is the temperature near the rotating filter wheel that holds the individual filters and the blue line is the temperature of the shortwave-infrared detector. The temperature control setting of this POM- 02 is $20^{\circ} \mathrm{C}$. As heat is generated from the electric circuit inside the POM-02, the inside temperature exceeds $20^{\circ} \mathrm{C}$ even if the ambient temperature is less than $20^{\circ} \mathrm{C}$. The heater stops when the inside temperature of the POM- 02 exceeds $20^{\circ} \mathrm{C}$. However, as there is no cooling mechanism, the temperature inside the POM-02 rises as the ambient temperature increases. When the ambient temperature is very low, the temperature does not rise to $20^{\circ} \mathrm{C}$ because the heater is not powerful enough. For example, when the ambient temperature was about $-20^{\circ} \mathrm{C}$, the internal temperature was about $0^{\circ} \mathrm{C}$. The ambient temperature was varied in the order of $40,20,0,-20,0,20,40$, and $20^{\circ} \mathrm{C}$. As the mounting position of the temperature sensor and the thermal structure of the instrument were different for each product, not every POM-02 temperature responds in the same way.

In Fig. 2, the relation between the sensor output and the inside temperature near the filter wheel for POM-02 (calibration reference) is shown. The sensor output is normalized by the sensor output at $20^{\circ} \mathrm{C}$. The ambient environmental temperature was varied from -20 to $40^{\circ} \mathrm{C}$. The detector used for wavelengths shorter than $1020 \mathrm{~nm}$ was a Si photodiode, and the detector for the 1225, 1627, and $2200 \mathrm{~nm}$ wavelengths was a thermoelectrically cooled InGaAs photodiode. In this study, the former wavelength region is referred to as the "visible and near-infrared region" and the latter is the "shortwave-infrared region".

The temperature dependence of the sensor output in the 340 and $2200 \mathrm{~nm}$ channels was larger than in the other channels. The range of the atmospheric temperature at Tsukuba was about -5 to $35^{\circ} \mathrm{C}$ (the range of the monthly mean temperature was 2.7 to $25.5^{\circ} \mathrm{C}$ ), and the resulting inside temperatures were between 15 and $35^{\circ} \mathrm{C}$ (Fig. 1), and the change in the instrument response was less than $1.5 \%$, except for the
340 and $2200 \mathrm{~nm}$ channels. The temperature dependence of the sensor output varies with the channel.

In the $340 \mathrm{~nm}$ channel, the sensor output decreased by $7 \%$ when the internal temperature increased from 20 to $40^{\circ} \mathrm{C}$. In the $2200 \mathrm{~nm}$ channel, the sensor output decreased by a rate of $5 \%$ to $6 \%$ per $10^{\circ} \mathrm{C}$ of temperature increase. Therefore, the temperature dependence of the sensor output cannot be ignored in these two channels.

In Fig. 3, the temperature dependence of the sensor output for POM-02 (Tsukuba) is shown. The temperature dependence of the sensor output in the $380 \mathrm{~nm}$ and $2200 \mathrm{~nm}$ channels for this POM-02 are larger and smaller, respectively, than that for the calibration reference POM-02. In the 340 and $380 \mathrm{~nm}$ channels, the rate of sensor output decrease was about $1.5 \%$ per $10^{\circ} \mathrm{C}$, and in the $2200 \mathrm{~nm}$ channel, the rate of sensor output decrease was about $3 \%$ per $10^{\circ} \mathrm{C}$. In the other channels, the temperature dependence of the sensor output was less than $1 \%$ for temperatures between 0 and $40^{\circ} \mathrm{C}$.

The temperature dependence of the detector sensitivity, as shown in the specifications data sheet of the detector (https://www.hamamatsu.com/resources/pdf/ssd/s1336_ series_kspd1022e.pdf, last access: 18 September 2018) is almost zero, i.e., indistinguishable from zero in the sensitivity diagram, at wavelengths from 300 to $950 \mathrm{~nm}$. At a wavelength of $1020 \mathrm{~nm}$, it is about $0.2 \%$ per ${ }^{\circ} \mathrm{C}$. At wavelengths of 1225,1627 , and $2200 \mathrm{~nm}$, they are almost zero, $-0.05 \%$ per degree, and $0.02 \%$ per ${ }^{\circ} \mathrm{C}$, respectively (https://www.hamamatsu.com/resources/pdf/ssd/ g12183_series_kird1119e.pdf, last access: 18 September 2018). The temperature dependencies of the sensor output shown in Figs. 2 and 3 are characteristic of the entire instrument. Some channels exhibit greater temperature dependence than the temperature dependence of the detector.

Though only two examples were shown here, the temperature dependence of the sensor output differed between instruments. If we want to determine the temperature dependence of the sensor output precisely, we need to measure it for each instrument or only use channels with a small temperature dependence.

\section{Langley method}

In this section, the Langley method is briefly reviewed and the Langley method used in this study is described. Before investigating the RMSE of the IML method, first the precision of the normal Langley method and the transfer of the calibration constant are investigated. The transferred calibration constant can be obtained by comparing side by side measurements of the direct solar irradiance. 
(a)

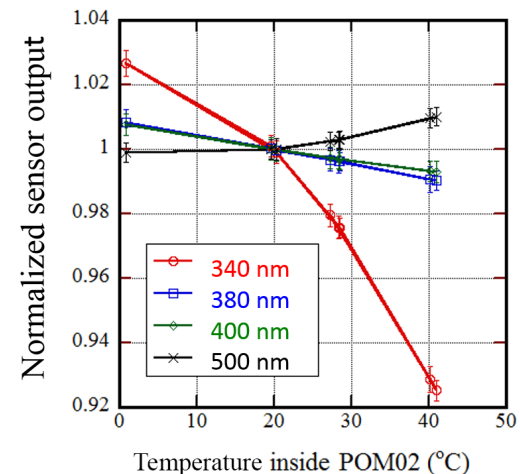

(c)

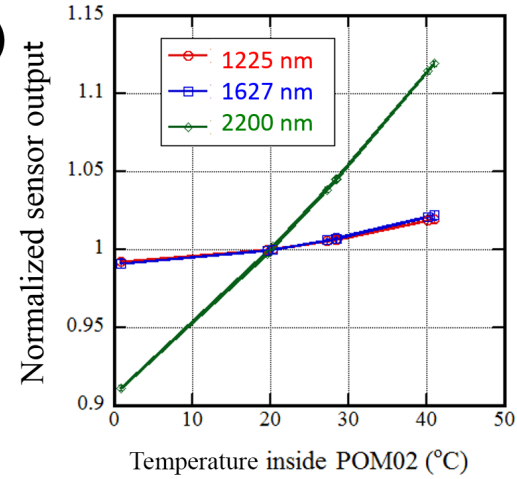

(b)

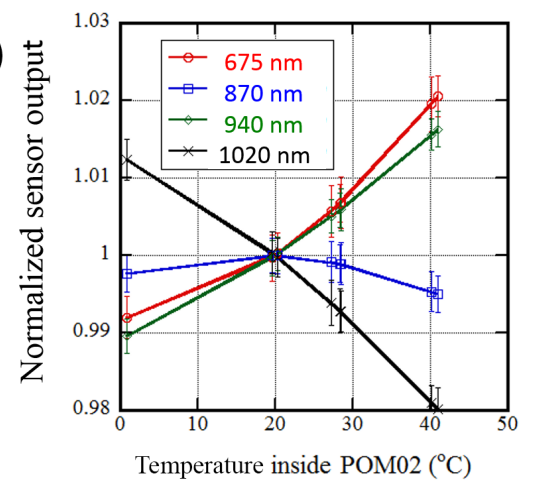

Figure 2. Relation between the sensor output and the inside temperature near the filter wheel for POM-02 (calibration reference). The sensor output is normalized by the output at $20^{\circ} \mathrm{C}$. The error bars are the standard deviation. Panel (a) represents 340, 380, 400, and 500 nm. Panel (b) represents 675, 870, 940, and $1020 \mathrm{~nm}$. Panel (c) represents 1225, 1627, and $2200 \mathrm{~nm}$.

(a)

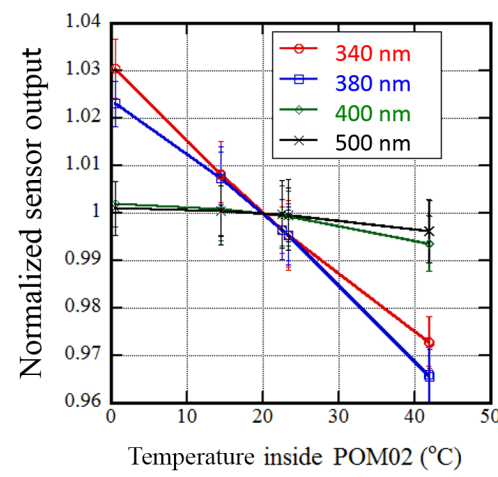

(c)

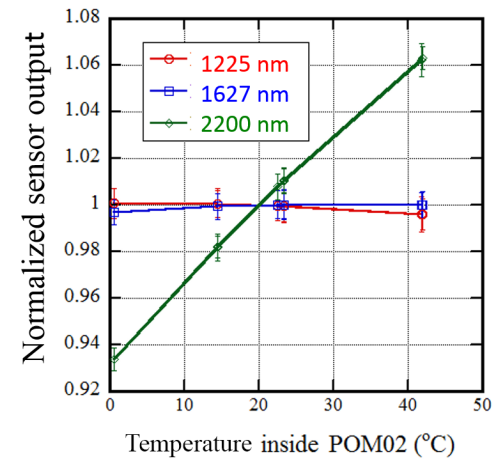

(b)

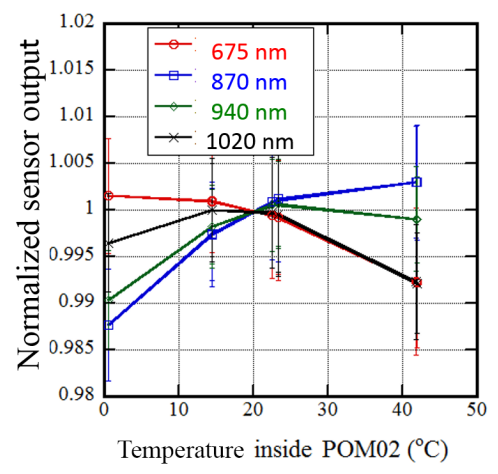

Figure 3. Same as Fig. 2 but for POM-02 (Tsukuba). 


\subsection{Brief review of Langley method}

According to the Beer-Lambert-Bouguer attenuation law, the directly transmitted monochromatic solar irradiance $F(\lambda)$ at wavelength $\lambda$ is as follows:

$F(\lambda)=\frac{F_{0}(\lambda)}{R^{2}} \exp \left(-\int_{z_{0}}^{\infty} k(\lambda, s) \mathrm{d} s\right)$,

where $F_{0}(\lambda)$ is the monochromatic solar irradiance at wavelength $\lambda$, at the mean earth-sun distance (1 AU), $R$ is the earth-sun distance in $\mathrm{AU}$, and $k(\lambda, s)$ is the total spectral extinction coefficient at position $s$. The integral of $k(\lambda, s)$ is the optical path length, and the integration is done along the path of the solar beam. In Eq. (2), several atmospheric components contribute to $k(\lambda, s)$ : Rayleigh scattering by air molecules, extinction by aerosol and cloud particles, absorbing gas such as water vapor and ozone, etc.

When the extinction coefficient is composed of several components, Eq. (2) becomes

$F(\lambda)=\frac{F_{0}(\lambda)}{R^{2}} \exp \left(-\sum_{i} \int_{z_{0}}^{\infty} k_{i}(\lambda, s) \mathrm{d} s\right)$.

Introducing the vertical optical thickness (or optical depth) for each component provides the following equation:

$\tau_{i}(\lambda)=\int_{z_{0}}^{\infty} k_{i}(\lambda, z) \mathrm{d} z$

where the extinction coefficient for the $i$ th component is integrated in the vertical direction (Liou, 2002).

Using the optical depth $\tau_{i}(\lambda)$, the optical path length is written as follows:

$m_{i}(\theta) \tau_{i}(\lambda)=\int_{z_{0}}^{\infty} k_{i}(\lambda, s) \mathrm{d} s$,

where $m_{i}(\theta)$ is the air mass for the $i$ th component, and $\theta$ is the solar zenith angle. The air mass varies with the solar zenith angle, and for small $\theta$ may be approximated by $1 / \cos (\theta)$. For large zenith angles $\left(\theta>60^{\circ}\right)$, the sphericity and atmospheric refraction must be taken into account. As $m_{i}(\theta)$ also depends on the vertical distribution of a component, $m_{i}(\theta)$ is different for each component.

Substituting Eq. (5) into Eq. (3) gives the following equation:

$F(\lambda)=\frac{F_{0}(\lambda)}{R^{2}} \exp \left(-\sum_{i} m_{i}(\theta) \tau_{i}(\lambda)\right)$.

Traditionally, the directly transmitted solar irradiance is represented as follows:
$F(\lambda)=\frac{F_{0}(\lambda)}{R^{2}} \exp \left(-m_{\mathrm{T}}(\theta) \tau_{\mathrm{T}}(\lambda)\right)$,

where $m_{\mathrm{T}}(\theta)$ is the total air mass and $\tau_{\mathrm{T}}(\lambda)$ is the total optical depth.

To obtain a measurable radiometer signal, $F(\lambda)$ is measured with some small but non-zero finite bandwidth at the selected wavelength and finite field of view (Shaw, 1982). Spectral filter radiometers with a bandwidth of about $10 \mathrm{~nm}$ or less in the visible and near infrared region were recommended and used for accurate measurements (Shaw, 1976, 1982; Reagan et al., 1986; Bruegge et al., 1992; Schmid and Wehrli, 1995; Holben et al., 1998; Kazadzis et al., 2017).

The solar direct irradiance spectrally averaged by the spectral response function is written as follows:

$\bar{F}\left(\lambda_{0}\right)=$

$\int_{\Delta \lambda} \phi(\lambda) \frac{F_{0}(\lambda)}{R^{2}} \exp \left(-\sum_{i} m_{i}(\theta) \tau_{i}(\lambda)\right) \mathrm{d} \lambda / \int_{\Delta \lambda} \phi(\lambda) \mathrm{d} \lambda$,

where $\bar{F}\left(\lambda_{0}\right)$ is the solar direct irradiance spectrally averaged at the center wavelength $\lambda_{0}$, and $\varphi(\lambda)$ is the filter response function.

As the wavelength dependence of the molecular scattering coefficient, extinction coefficient by aerosols, and continuous absorption coefficient by gas are small, these values are approximated by the value at the center wavelength $\lambda=\lambda_{0}$. The extraterrestrial solar irradiance is approximated by the filterweighted value. However, in the gas absorption band composed of many absorption lines, such as the $940 \mathrm{~nm}$ channel, the filter-weighted transmittance does not follow the BeerLambert-Bouguer attenuation law,

$\bar{F}\left(\lambda_{0}\right)=\frac{\bar{F}_{0}\left(\lambda_{0}\right)}{R^{2}} \exp \left(-\sum_{i} m_{i}(\theta) \tau_{i}\left(\lambda_{0}\right)\right) \bar{T}_{\text {gas }}\left(\lambda_{0}, \theta\right)$,

where

$\bar{T}_{\text {gas }}\left(\lambda_{0}, \theta\right)=$

$\int_{\Delta \lambda} \phi(\lambda) \exp \left(-m_{\text {gas }}(\theta) \tau_{\text {gas }}(\lambda)\right) \mathrm{d} \lambda / \int_{\Delta \lambda} \phi(\lambda) \mathrm{d} \lambda$,

and $\tau_{\text {gas }}$ is the optical depth of the gas absorption lines.

When estimating the optical depth of the aerosol from measurement of the direct solar irradiance, the wavelength range where the absorption by gas is as small as possible is chosen (Shaw, 1982). When estimating the precipitable water vapor, a wavelength range of $940 \mathrm{~nm}$ is often chosen.

Considering molecular scattering, absorption by ozone (Chappuis bands, Huggins bands), extinction by aerosol, and absorption by gas absorption lines, Eq. (9) becomes as follows: 


$$
\begin{aligned}
\bar{F}\left(\lambda_{0}\right) & =\frac{\bar{F}_{0}\left(\lambda_{0}\right)}{R^{2}} \exp \left(-m_{\mathrm{R}}(\theta) \tau_{\mathrm{R}}\left(\lambda_{0}\right)\right. \\
& \left.-m_{\mathrm{O}_{3}}(\theta) \tau_{\mathrm{O}_{3}}\left(\lambda_{0}\right)-m_{\mathrm{aer}}(\theta) \tau_{\mathrm{aer}}\left(\lambda_{0}\right)\right) \bar{T}_{\mathrm{gas}}\left(\lambda_{0}, \theta\right) \\
& =\frac{\bar{F}_{0}\left(\lambda_{0}\right)}{R^{2}} \exp \left(-m_{\mathrm{T}}(\theta) \tau_{\mathrm{T}}\left(\lambda_{0}\right)\right) \bar{T}_{\text {gas }}\left(\lambda_{0}, \theta\right),
\end{aligned}
$$

where $m_{\mathrm{R}}, m_{\mathrm{O}_{3}}$, and $m_{\text {aer }}$ are the air mass for molecular scattering (Rayleigh scattering), ozone, and aerosol, respectively, and $\tau_{\mathrm{R}}, \tau_{\mathrm{O}_{3}}$, and $\tau_{\text {aer }}$ are the optical depths for molecular scattering, ozone, and aerosol, respectively.

If the sensor output is proportional to the input energy, the following equation can be written.

$$
\begin{aligned}
\bar{V}\left(\lambda_{0}\right) & =\frac{\bar{V}_{0}\left(\lambda_{0}\right)}{R^{2}} \exp \left(-m_{\mathrm{R}}(\theta) \tau_{\mathrm{R}}\left(\lambda_{0}\right)\right. \\
& \left.-m_{\mathrm{O}_{3}}(\theta) \tau_{\mathrm{O}_{3}}\left(\lambda_{0}\right)-m_{\text {aer }}(\theta) \tau_{\text {aer }}\left(\lambda_{0}\right)\right) \bar{T}_{\text {gas }}\left(\lambda_{0}, \theta\right) \\
& =\frac{\bar{V}_{0}\left(\lambda_{0}\right)}{R^{2}} \exp \left(-m_{\mathrm{T}}(\theta) \tau_{\mathrm{T}}\left(\lambda_{0}\right)\right) \bar{T}_{\text {gas }}\left(\lambda_{0}, \theta\right)
\end{aligned}
$$

Here, the contribution of the diffuse radiances in the FOV is neglected.

If absorption by gas absorption lines can be ignored, Eq. (12) can be written as follows:

$$
\begin{aligned}
\bar{V}\left(\lambda_{0}\right) & =\frac{\bar{V}_{0}\left(\lambda_{0}\right)}{R^{2}} \exp \left(-m_{\mathrm{R}}(\theta) \tau_{\mathrm{R}}\left(\lambda_{0}\right)\right. \\
& \left.-m_{\mathrm{O}_{3}}(\theta) \tau_{\mathrm{O}_{3}}\left(\lambda_{0}\right)-m_{\text {aer }}(\theta) \tau_{\mathrm{aer}}\left(\lambda_{0}\right)\right) \\
& =\frac{\bar{V}_{0}\left(\lambda_{0}\right)}{R^{2}} \exp \left(-m_{\mathrm{T}}(\theta) \tau_{\mathrm{T}}\left(\lambda_{0}\right)\right) .
\end{aligned}
$$

Taking the logarithm of Eq. (13) leads to

$\ln \left(\bar{V}\left(\lambda_{0}\right) R^{2}\right)=\ln \bar{V}_{0}\left(\lambda_{0}\right)-m_{\mathrm{T}}(\theta) \tau_{\mathrm{T}}\left(\lambda_{0}\right)$.

If a series of measurements is taken over a range of $m_{\mathrm{T}}(\theta)$, during which the optical depth $\tau_{\mathrm{T}}\left(\lambda_{0}\right)$ remains constant, $\bar{V}_{0}\left(\lambda_{0}\right)$ may be determined from the ordinate intercept of a least squares fit when one plots the left-hand side of Eq. (14) vs. $m_{\mathrm{T}}(\theta)$. This procedure is commonly known as the Langley-plot calibration. $\bar{V}_{0}\left(\lambda_{0}\right)$ is the sensor output for the extraterrestrial solar irradiance at $1 \mathrm{AU}$ earth-sun distance, and is called the calibration constant.

The Langley method, which is performed assuming the same air mass of air molecule scattering for all attenuating substances is sometimes called the normal Langley method (Reagan et al., 1986) or the traditional Langley method (Schmid and Wehrli, 1995). In this paper, "normal Langley" is used.

When the different components contributing to the attenuation have different vertical distributions, each component has a different dependence of the air mass on the solar zenith angle. In the refined Langley method, the contribution to the attenuation of each component is treated separately (Thomason et al., 1983; Guzzi et al., 1985; Reagan et al., 1986; Bruegge et al., 1992; Schmid and Wehrli, 1995).
The effect of the vertical distribution of ozone on the determination of the calibration constant was examined by Thomason et al. (1983). According to their results, the influence of the vertical distribution of ozone is large when $0.1 \%$ accuracy is required, but at a wavelength of $500 \mathrm{~nm}$, the error is at most $0.1 \%$, even if using the air mass of the uniform mixture atmosphere.

The presence of thick stratospheric aerosol layers, such as those measured immediately after major volcanic eruptions including the Pinatubo eruption in July 1991, may cause the air mass to be different from under ordinary conditions (Russell et al., 1993; Dutton et al., 1994).

For the water vapor absorption band at a wavelength of $940 \mathrm{~nm}$, the Beer-Lambert-Bouguer law is not valid. In this region, the modified Langley method is often used (Reagan et al., 1987a; Bruegge et al., 1992; Schmid and Wehrli 1995). In the modified Langley method, the transmittance is approximated by an empirical formula. In Sect. 7, this modified Langley method is applied to the on-site measurement data.

\subsection{Normal Langley method}

In this section, the precision of the normal Langley is investigated,

$$
\begin{aligned}
& \bar{V}\left(\lambda_{0}\right)=\frac{\bar{V}_{0}\left(\lambda_{0}\right)}{R^{2}} \exp \left(-m_{\mathrm{R}}(\theta) \tau_{\mathrm{R}}\left(\lambda_{0}\right)\right. \\
& \left.\quad-m_{\text {aer }}(\theta) \tau_{\text {aer }}\left(\lambda_{0}\right)\right) \bar{T}_{\text {gas }}\left(\lambda_{0}, \theta\right) \\
& \approx \frac{\bar{V}_{0}\left(\lambda_{0}\right)}{R^{2}} \exp \left(-m_{\mathrm{R}}(\theta)\left(\tau_{\mathrm{R}}\left(\lambda_{0}\right)+\tau_{\text {aer }}\left(\lambda_{0}\right)\right) \bar{T}_{\text {gas }}\left(\lambda_{0}, \theta\right),\right.
\end{aligned}
$$

where $m_{\text {aer }}(\theta)$ is approximated by $m_{\mathrm{R}}(\theta) . m_{\mathrm{R}}(\theta)$ is calculated using the formula from Kasten and Young (1989). To compute $m_{\text {aer }}(\theta)$ exactly, we would need a vertical profile of the aerosol extinction coefficient; however, it is difficult to obtain the vertical profile of the aerosol extinction coefficient. Therefore, $m_{\mathrm{R}}(\theta)$ is often used instead of $m_{\mathrm{aer}}(\theta)$ (Schmid and Wehrli, 1995; Holben et al., 1998).

In the case of "no gas absorption", the following equation is used:

$\bar{V}\left(\lambda_{0}\right)=\frac{\bar{V}_{0}\left(\lambda_{0}\right)}{R^{2}} \exp \left(-m_{\mathrm{T}}(\theta) \tau_{\mathrm{T}}\left(\lambda_{0}\right)\right)$,

where $m_{\mathrm{T}}(\theta)=m_{\mathrm{R}}(\theta)$; the same air mass is assumed for all attenuators.

Although the term for the gas line absorption is not written explicitly, when the line absorption is in the region of the weak line limit, the absorptance (=1- transmittance) is proportional to the sum of the line absorption strengths. Therefore, the transmittance changes exponentially with the air mass.

In the case of "gas absorption", the following equation is used: 
(a)

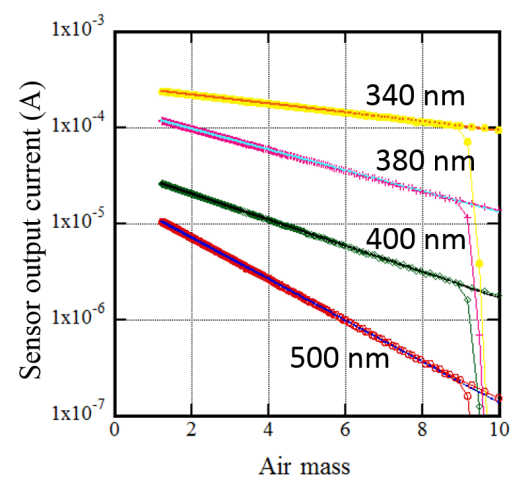

(c)

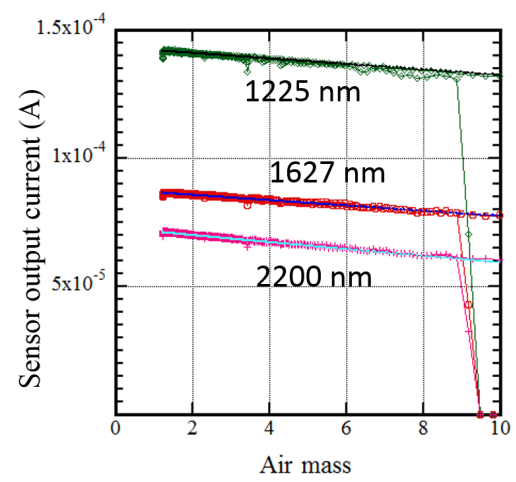

(b)

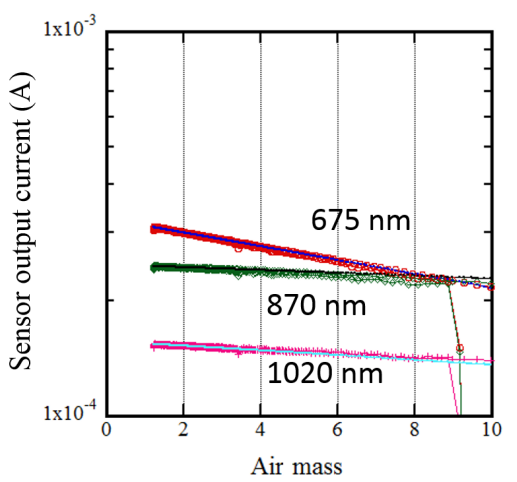

Figure 4. Examples of Langley plots using the data obtained at MLO, on 3 November 2015. The sensor output of POM-02 is current: the unit is ampere $(\mathrm{A})$.

$\bar{V}\left(\lambda_{0}\right)=$

$\frac{\bar{V}_{0}\left(\lambda_{0}\right)}{R^{2}} \exp \left(-m_{\mathrm{R}}(\theta)\left(\tau_{\mathrm{R}}\left(\lambda_{0}\right)+\tau_{\text {aer }}\left(\lambda_{0}\right)\right) \bar{T}_{\text {gas }}\left(\lambda_{0}, \theta\right)\right)$.

When calculating $\bar{T}_{\text {gas }}\left(\lambda_{0}, \theta\right)$, the absorption of water vapor, carbon dioxide, ozone, methane, carbon monoxide, and oxygen is only taken into consideration when the absorptions by these gases are in the range of the response function.

It is recommended that the measurements for calibration by the Langley method be conducted at a high mountain observatory. The MLO is one of the most suitable places to make measurements for calibration by the Langley method. Though the air at MLO is exceedingly transparent, it is affected in late morning and afternoon hours by marine aerosol that reaches the observatory during the marine inversion boundary layer breakdown under solar heating. Typically, by late morning, the downslope winds change to upslope winds, which bring moisture and aerosol-rich marine boundary layer air up the mountainside, resulting in an abundance of orographic clouds at the observatory (Shaw, 1983; Perry et al., 1999). Therefore, using data taken in the morning is recommended and used (Shaw, 1982; Dutton et al., 1994; Holben et al., 1998).

In AERONET, the variability of the determined calibration coefficient as measured by the coefficient of variation or the relative standard deviation ( $\mathrm{CV}$ or RSD, standard deviation/mean) is $\sim 0.25-0.50 \%$ for the visible and near-infrared wavelengths, $\sim 0.5-2 \%$ for ultraviolet and $\sim 1-3 \%$ for the water vapor channel (Holben et al., 1998).

In this study, though using data taken in the morning is recommended, both morning and afternoon data were used for the Langley plot. Our observation period for calibration by the Langley method is short, about 1 month, so we want to use all the data effectively. Furthermore, the quality of the Langley plot can be checked by an analysis of the residuals; for acceptable data, no trend or systematic pattern is visible when the residuals vs. air mass are plotted. The residuals were carefully checked and most results for the afternoon data were not included in the analysis.

Figure 4 shows an example of a Langley plot using the data obtained at MLO. In these Langley plots, the data in both the morning and afternoon are plotted. The linear regression lines were determined using the data with an air mass range between 2 and 6 , in the morning. In these examples, the data in the afternoon lies close to the regression line fitted to the morning data. On such days, the Langley plot was also applied to the afternoon data. From these examples, by using data taken at a location with suitable conditions, it is possible to determine a precise calibration line.

At MLO, 10 to 20 measurements for the Langley calibration can usually be taken over a period of 30 to 40 continuous observation days depending on the weather conditions. 
Table 2. Example of calibration constants $\left(V_{0}\right)$ determined by using the data taken at MLO.

\begin{tabular}{|c|c|c|c|c|c|c|c|c|c|c|c|c|}
\hline & Wavelength (nm) & 340 & 380 & 400 & 500 & 675 & 870 & 940 & 1020 & 1225 & 1627 & 2200 \\
\hline \multirow[t]{3}{*}{ Case 1} & $V_{0}(\mathrm{NGABS}, \mathrm{NTPC})\left(\times 10^{-4}\right)$ & 0.19885 & 0.39332 & 1.6412 & 2.7745 & 3.2852 & 2.4791 & 1.9936 & 1.5513 & 0.88278 & 1.4410 & 0.72407 \\
\hline & $\mathrm{SD}\left(\times 10^{-4}\right)$ & 0.00112 & 0.00166 & 0.0059 & 0.0082 & 0.0058 & 0.0146 & 0.1620 & 0.0080 & 0.00889 & 0.0086 & 0.00411 \\
\hline & $\mathrm{CV}\left(=\mathrm{SD} / V_{0}\right)$ & 0.00564 & 0.00421 & 0.0036 & 0.0030 & 0.0018 & 0.0059 & 0.0812 & 0.0052 & 0.01007 & 0.0060 & 0.00567 \\
\hline \multirow[t]{3}{*}{ Case 2} & $V_{0}(\mathrm{NGABS}, \mathrm{TPC})\left(\times 10^{-4}\right)$ & 0.20470 & 0.39515 & 1.6473 & 2.7638 & 3.2581 & 2.4825 & 1.9814 & 1.5643 & 0.87554 & 1.4287 & 0.68906 \\
\hline & $\mathrm{SD}\left(\times 10^{-4}\right)$ & 0.00187 & 0.00160 & 0.0058 & 0.0079 & 0.0068 & 0.0144 & 0.1612 & 0.0094 & 0.00928 & 0.0090 & 0.00860 \\
\hline & $\mathrm{CV}\left(=\mathrm{SD} / V_{0}\right)$ & 0.00915 & 0.00406 & 0.0035 & 0.0028 & 0.0021 & 0.0058 & 0.0814 & 0.0060 & 0.01060 & 0.0063 & 0.01248 \\
\hline \multirow[t]{3}{*}{ Case 3} & $V_{0}(\mathrm{GABS}, \mathrm{NTPC})\left(\times 10^{-4}\right)$ & 0.19885 & 0.39331 & 1.6412 & 2.7746 & 3.2852 & 2.4791 & 2.3105 & 1.5516 & 0.88512 & 1.4422 & 0.73047 \\
\hline & $\mathrm{SD}\left(\times 10^{-4}\right)$ & 0.00112 & 0.00165 & 0.0059 & 0.0082 & 0.0058 & 0.0146 & 0.2119 & 0.0080 & 0.00822 & 0.0084 & 0.00428 \\
\hline & $\mathrm{CV}\left(=\mathrm{SD} / V_{0}\right)$ & 0.00564 & 0.00420 & 0.0036 & 0.0029 & 0.0018 & 0.0059 & 0.0917 & 0.0051 & 0.00928 & 0.0058 & 0.00587 \\
\hline \multirow[t]{7}{*}{ Case 4} & $V_{0}(\mathrm{GABS}, \mathrm{TPC})\left(\times 10^{-4}\right)$ & 0.20469 & 0.39516 & 1.6473 & 2.7640 & 3.2582 & 2.4825 & 2.2968 & 1.5651 & 0.87843 & 1.4300 & 0.69666 \\
\hline & $\mathrm{SD}\left(\times 10^{-4}\right)$ & 0.00188 & 0.00161 & 0.0058 & 0.0078 & 0.0068 & 0.0144 & 0.2092 & 0.0097 & 0.00861 & 0.0090 & 0.00872 \\
\hline & $\mathrm{CV}\left(=\mathrm{SD} / V_{0}\right)$ & 0.00917 & 0.00407 & 0.0035 & 0.0028 & 0.0021 & 0.0058 & 0.0911 & 0.0062 & 0.00980 & 0.0063 & 0.01251 \\
\hline & No. of data & 22 & 22 & 22 & 22 & 22 & 22 & 22 & 22 & 22 & 22 & 22 \\
\hline & Case 1 / Case $4-1.0$ & -0.0285 & -0.0047 & -0.0037 & 0.0038 & 0.0083 & -0.0014 & -0.1320 & -0.0088 & 0.0050 & 0.0077 & 0.0393 \\
\hline & Case 2 / Case $4-1.0$ & 0.0000 & 0.0000 & 0.0000 & -0.0001 & 0.0000 & 0.0000 & -0.1373 & -0.0005 & -0.0033 & -0.0009 & -0.0109 \\
\hline & Case 3 / Case $4-1.0$ & -0.0285 & -0.0047 & -0.0037 & 0.0038 & 0.0083 & -0.0014 & 0.0060 & -0.0086 & 0.0076 & 0.0085 & 0.0485 \\
\hline
\end{tabular}

Bold: ABS(ERR) > 0.03; italic: ABS(ERR) <0.01; $V_{0}$ : mean value of calibration constant in 2015 MLO observation (the unit of $V_{0}$ is ampere(A)); SD: standard deviation; CV: coefficient of variation or relative standard deviation ( $\left.=\mathrm{SD} / V_{0}\right)$; GABS: consideration of gas absorption; NGABS: no consideration of gas absorption; TPC: consideration of temperature correction; NTPC: no consideration of temperature correction.

Shortwave-infrared channels $(1225,1627$, and $2200 \mathrm{~nm})$ are more sensitive to weather conditions than channels in the visible and near-infrared range, because there are water vapor absorption bands in the shortwave-infrared channel and the water vapor in the atmosphere tends to fluctuate.

Table 2 shows the calibration constants $\left(V_{0}\right)$ determined using the data taken from October 2015 to November 2015 at MLO. The calibration constants were calculated for the following four cases:

- Case 1 - no gas absorption, and no temperature correction (NGABS, NTPC);

- Case 2 - no gas absorption, and temperature correction (NGABS, TPC);

- Case 3 - gas absorption, and no temperature correction (GABS, NTPC);

- Case 4 - gas absorption, and temperature correction (GABS, TPC).

The $\mathrm{CV}$ of the calibration constants $\left(\mathrm{SD} / V_{0}, \mathrm{SD}\right.$ is the standard deviation, $V_{0}$ is the mean) were $0.2 \%$ to $1.3 \%$ except in the $940 \mathrm{~nm}$ channel, where the mean $V_{0}$ and standard deviation were calculated from all data with weighting. The weight is calculated from the RMSE of the regression line and the observations (see Appendix A). From these results, it can be seen that the calibration constant can be reliably determined by the normal Langley method, using the data taken at MLO. In AERONET, similar results were obtained (Holben et al., 1998).

Based on the ratio of Case 3 / Case 4, the effect of the temperature dependence on the 340 and $2200 \mathrm{~nm}$ channels was about $3 \%$ and $5 \%$, respectively. In the other channels, the effect of the temperature dependence is less than $0.9 \%$. The range of the atmospheric temperature was about 5 to $15^{\circ} \mathrm{C}$ when the measurements for the calibration at MLO were conducted. Therefore, the effect of the temperature dependence on the sensor output is small.

From the ratio of Case 2 / Case 4, the effect of the gas absorption is more than $10 \%$ in the $940 \mathrm{~nm}$ channel, less than $0.4 \%$ in the 1225 and $1627 \mathrm{~nm}$ channels, and about $1 \%$ in the $2200 \mathrm{~nm}$ channel. These channels have weak gas absorption by water vapor, $\mathrm{CO}_{2}$, and $\mathrm{CO}$.

As seen from the ratio of Case $1 /$ Case 4 , the calibration constants, except in the 340,940 , and $2200 \mathrm{~nm}$ channels, can be determined with a difference of less than $1 \%$ without consideration of the temperature effect and gas absorption by using the data taken at MLO.

The results shown here were obtained using the data taken at MLO.

To calibrate the $940 \mathrm{~nm}$ channel, the vertical distribution of water vapor is necessary. The vertical distribution of water vapor is constructed with radiosonde data from the nearest site, precipitable water vapor (PWV) by the Global Positioning System (GPS), and the relative humidity is measured at MLO, and the transmittance is calculated as in Uchiyama et al. (2014). The radiosonde measurements were taken twice a day, and the PWV by GPS were the 30 min averages. The temporal resolution of these data is not high enough to precisely determine the vertical distribution of the water vapor, resulting in a large error in the calibration constant in the $940 \mathrm{~nm}$ channel.

Figure 5 shows the annual multi-year variation of the calibration constants $\left(V_{0}\right)$ for POM-02 (calibration reference). The lens in the visible and near-infrared region (Si photodiode region) was replaced in 2013 and the interference filter in the $1225 \mathrm{~nm}$ channel was replaced in 2014. As insufficient 

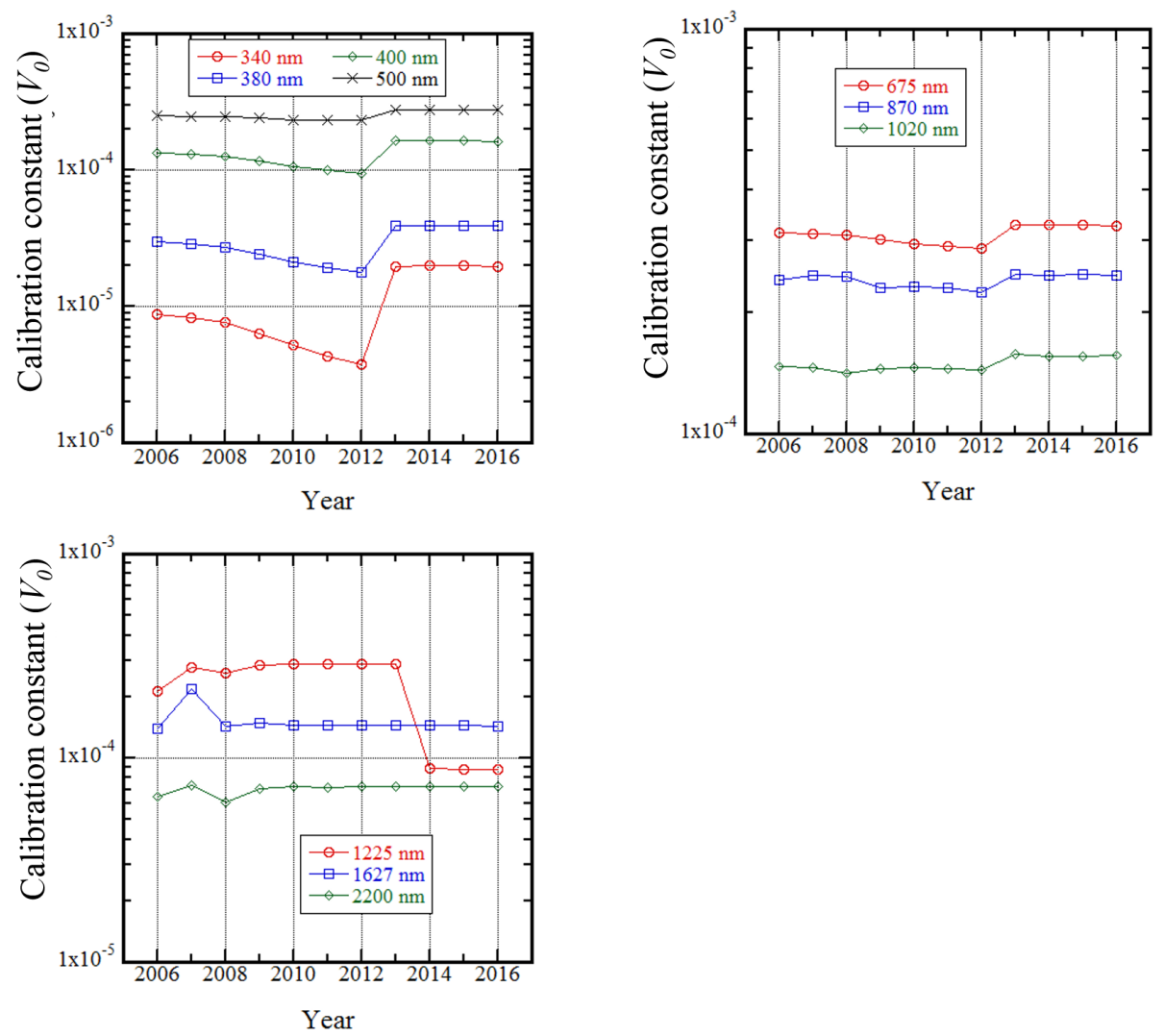

Figure 5. Annual variation of the calibration constants $\left(V_{0}\right)$ for POM-02 (calibration reference). The sensor output of POM-02 is current. The unit of $V_{0}$ is ampere (A).

data were taken due to bad weather conditions in 2007 and 2008, the calibration could not be performed with sufficient precision. Therefore, the degradation is not smooth in some channels.

In general, the degradation at shorter wavelengths is larger than at longer wavelengths in the Si photodiode region. During the period from 2006 to 2012, the changes of $V_{0}$ in the 340,380 , and $400 \mathrm{~nm}$ channels were $-10 \%$ per year, $-7 \%$ per year, and $-4 \%$ per year, respectively. The changes of $V_{0}$ in the 500,675 , and $870 \mathrm{~nm}$ channels were about $-1 \%$ per year, and that in the $1020 \mathrm{~nm}$ channel was almost zero. These results indicate that calibration is necessary at least once a year to monitor the degradation of $V_{0}$. After replacing the lens in 2013, the degradation of the 340 , and $380 \mathrm{~nm}$ channels became smaller. The manufacturer of the sky radiometer may have upgraded the lens.

The calibration in the shortwave-infrared channels (1225, 1627 , and $220 \mathrm{~nm}$ ) is sensitive to weather conditions. Therefore, the interannual variation of the calibration constants in these channels is not always smooth. However, from 2009 to 2016, the annual change of the calibration constant in the shortwave-infrared channels was less than $1 \%$.

\section{3 $\quad V_{0}$ calibration transfer by direct solar measurement}

The calibration constant for one instrument can be used to estimate the calibration constant for another instrument by comparison with the simultaneous measurements of the solar direct irradiance.

The measurements for the comparison were made every minute using the same data acquisition system. It takes about $10 \mathrm{~s}$ to measure 11 channels at each time. Measurements by all POM-02 are done at the same time. The calibration of time is carried out every hour using the NTP (Network Time Protocol) server. For data comparison, only air mass data less than 2.5 were used on clear days. The comparisons were made under the assumption that the filter response functions of POM-02 are the same. When there is a difference in the filter, the relationship between the outputs of both becomes nonlinear. When this greatly deviated from the linear relationship, the characteristics of either filter had changed, and it is necessary to replace the filter.

Table 3 shows the results of the calibration constant transferred from POM-02 (calibration reference) to POM-02 (Tsukuba) and POM-02 (Fukuoka) in December 2014. The comparison measurements were conducted over 11 days for 
Table 3. Results of the calibration constant transferred from POM-02 (calibration reference) to POM-02 (Tsukuba) and POM-02 (Fukuoka) in December 2014.

\begin{tabular}{|c|c|c|c|c|c|c|c|c|c|c|c|}
\hline Site & \multicolumn{11}{|c|}{ Tsukuba } \\
\hline Period & \multicolumn{11}{|c|}{1 Dec 2015-1 Jan 2016} \\
\hline No. of days & \multicolumn{11}{|c|}{11} \\
\hline SN & \multicolumn{11}{|c|}{ PS1202091; calibrated by sky radiometer PS1207831 } \\
\hline Wavelength (nm) & 340 & 380 & 400 & 500 & 675 & 870 & 940 & 1020 & 1225 & 1627 & 2200 \\
\hline $\mathrm{V}_{0}\left(\times 10^{-4}\right)$ & 0.17469 & 0.25711 & 1.1621 & 2.9248 & 3.4792 & 2.2969 & 1.9900 & 0.79227 & 0.87065 & 1.4074 & 0.76879 \\
\hline $\mathrm{SD}\left(\times 10^{-4}\right)$ & 0.00050 & 0.00065 & 0.0021 & 0.0039 & 0.0045 & 0.0085 & 0.0087 & 0.00427 & 0.00321 & 0.0072 & 0.00402 \\
\hline $\mathrm{CV}\left(=\mathrm{SD} / V_{0}\right)$ & 0.00284 & 0.00253 & 0.0018 & 0.0013 & 0.0013 & 0.0037 & 0.0044 & 0.00539 & 0.00369 & 0.0051 & 0.00523 \\
\hline Site & \multicolumn{11}{|l|}{ Fukuoka } \\
\hline Period & \multicolumn{11}{|c|}{ 4-20 Dec 2015} \\
\hline No. of days & \multicolumn{11}{|c|}{8} \\
\hline $\mathrm{SN}$ & \multicolumn{11}{|c|}{ PS1202071; calibrated by sky radiometer PS1207831 } \\
\hline Wavelength (nm) & 340 & 380 & 400 & 500 & 675 & 870 & 940 & 1020 & 1225 & 1627 & 2200 \\
\hline$V_{0}\left(\times 10^{-4}\right)$ & 0.18374 & 0.23346 & 1.2332 & 2.9179 & 3.5176 & 2.3021 & 1.9827 & 1.8899 & 0.84113 & 1.2783 & 0.60461 \\
\hline $\mathrm{SD}\left(\times 10^{-4}\right)$ & 0.00028 & 0.00025 & 0.0014 & 0.0025 & 0.0041 & 0.0044 & 0.0106 & 0.0031 & 0.00279 & 0.0027 & 0.00113 \\
\hline $\mathrm{CV}\left(=\mathrm{SD} / V_{0}\right)$ & 0.00155 & 0.00107 & 0.0011 & 0.0008 & 0.0012 & 0.0019 & 0.0053 & 0.0016 & 0.00331 & 0.0021 & 0.00186 \\
\hline
\end{tabular}

$V_{0}$ : mean value; SD: standard deviation; $\mathrm{CV}$ : coefficient of variation or relative standard deviation $\left(=\mathrm{SD} / V_{0}\right)$.

POM-02 (Tsukuba) and 8 days for POM-02 (Fukuoka). The $\mathrm{CV}\left(\mathrm{SD} / V_{0}\right)$ is $0.1 \%$ to $0.5 \%$ depending on the wavelength, where mean $V_{0}$ is the arithmetic mean. The $\mathrm{CV}$ is $0.5 \%$ even for water vapor in the $940 \mathrm{~nm}$ channel; usually the fluctuation of the sensor output is large due to fluctuations in the water vapor amount. If the weighted mean is used as the expected value, a smaller $\mathrm{CV}$ than that of the arithmetic mean is expected.

The observations for the comparison depend on the weather conditions, but if there are calibrated instruments, it is the most straightforward and accurate way to transfer and determine the calibration constant for different instruments.

The JMA routine observation branch participated in the Fourth WMO Filter Radiometer Comparison in Davos, Switzerland, between 28 September and 16 October 2015 (Kazadzis et al., 2018). The calibration constant of POM02 used by them was transferred from the POM-02 (calibration reference) in this study by the method shown in this paper. In this inter-comparison campaign, the aerosol optical depths at the 500 and $875 \mathrm{~nm}$ wavelengths were compared. The results of the comparison showed that the JMA's POM02 met the World Meteorological Organization (WMO) criterion (WMO, 2005). This shows that the method shown in this study is adequate. The WMO criterion for the absolute differences of all instruments compared to the reference is defined as follows: "95\% of the measured data has to be within $0.005 \pm 0.001 / m$ " (where $m$ is the air mass).

\section{Improved Langley method}

\subsection{Brief review of improved Langley method}

In this section, the improved Langley method is briefly reviewed.

The solar direct irradiance at the surface normal to the solar beam based on the Beer-Lambert-Bouguer Law is written as follows:

$F=\frac{F_{0}}{R^{2}} \exp (-m \tau)$,

where $F$ and $F_{0}$ are the solar irradiance at the surface and the top of the atmosphere, respectively, $R$ is the earth-sun distance in astronomical units (AUs), $m=1 / \mu_{0}$ is the air mass, $\mu_{0}$ is the cosine of the solar zenith angle, and $\tau$ is the total atmospheric optical depth.

The single scattered radiance by aerosol and molecules in the almucantar of the sun is given by the following equation (Tanaka et al., 1986):

$$
\begin{aligned}
I_{1}\left(\mu_{0}, \phi\right) & =m \tau \omega_{0} P(\cos \Theta) \frac{F_{0}}{R^{2}} \exp (-m \tau) \\
& =m \tau_{\text {sca }} P(\cos \Theta) \frac{F_{0}}{R^{2}} \exp (-m \tau),
\end{aligned}
$$

where a one-layer plane-parallel atmosphere is assumed, $\tau_{\mathrm{sca}}=\tau \omega_{0}$ is the layer scattering optical depth, $\phi$ is the azimuthal angle measured from the solar principal plane, $\omega_{0}$ is the single scattering albedo, and $P(\cos \Theta)$ is the normalized phase function at the scattering angle $\Theta$. The improved Langley method is based on these equations.

If the sensor output is proportional to the input energy, the sensor output for the direct solar measurement can be written 
as follows:

$V=\frac{V_{0}}{R^{2}} \exp (-m \tau)$

where $V=C F, V_{0}=C F_{0}$, and $C$ is the proportional constant (sensitivity). The contribution of scattered light in the field of view is neglected.

The sensor output for the measured single scattering $V_{1}$ can be written as follows:

$$
\begin{aligned}
V_{1} & =C I_{1}\left(\mu_{0}, \phi\right) \Delta \Omega \\
& =C m \tau \omega_{0} P(\cos \Theta) \frac{F_{0}}{R^{2}} \exp (-m \tau) \Delta \Omega \\
& =m \tau \omega_{0} P(\cos \Theta) \frac{V_{0}}{R^{2}} \exp (-m \tau) \Delta \Omega,
\end{aligned}
$$

where $\Delta \Omega$ is the SVA.

From these equations, the following equations can be obtained:

$$
\begin{aligned}
& m \tau=\frac{V_{1}}{\omega_{0} P(\cos \Theta) \frac{V_{0}}{R^{2}} \exp (-m \tau) \Delta \Omega}, \\
& m \tau_{\mathrm{sca}}=\frac{V_{1}}{P(\cos \Theta) \frac{V_{0}}{R^{2}} \exp (-m \tau) \Delta \Omega} .
\end{aligned}
$$

Then from Eq. (20), we get the following equations:

$$
\begin{aligned}
\ln V R^{2} & =\ln V_{0}-m \tau \\
& =\ln V_{0}-m \tau_{\text {sca }} / \omega_{0}
\end{aligned}
$$

If $m, m \tau$, and $m \tau_{\text {sca }}$ can be obtained, the logarithm of the sensor output can be linearly fitted with $m, m \tau$, and $m \tau_{\text {sca }}$. The case when the $x$ axis is $m$ and the $y$ axis is $\ln V R^{2}$ corresponds to the normal Langley method, and the case when the $x$ axis is $m \tau$ or $m \tau_{\text {sca }}$ and the $y$ axis is $\ln V R^{2}$ is the improved Langley method. In the normal Langley method, the intersection of the $y$ axis and the regression line is $\ln V_{0}$ and the slope of the regression line is $-\tau$. There are two IML methods. If the $x$ axis is $m \tau$, the intersection of the $y$ axis and the regression line is $\ln V_{0}$ and the slope is -1 . Otherwise, when the $x$ axis is $m \tau_{\text {sca }}$, the intersection of the $y$ axis and the regression line is $\ln V_{0}$ and the slope is $-1 / \omega_{0}$. The SKYRAD package adopts the latter method.

In the SKYRAD package, two observable quantities are analyzed. One is the direct solar irradiance (Eq. 20), and the other is defined as follows:

$R(\lambda, \Theta)=\frac{V(\lambda, \Theta)}{V(\lambda, 0) m \Delta \Omega}$,

where $V(\lambda, \Theta)$ is the sensor output of the sky radiance measurement for the scattering angle $\Theta, \cos \Theta=\mu_{0}^{2}+(1-$ $\left.\mu_{0}^{2}\right) \cos \phi, \Delta \Omega$ is the SVA of the sky radiometer, and $V(\lambda, 0)$ is the radiometer output due to direct solar irradiance. This is the sky radiance normalized by the direct solar irradiance.

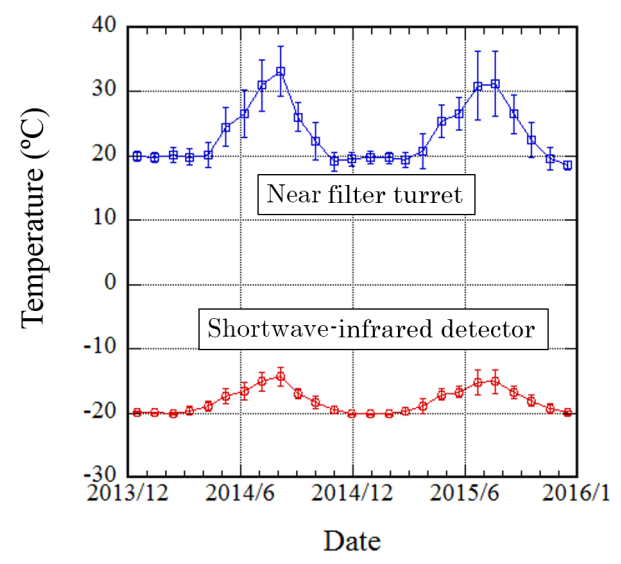

Figure 6. Monthly mean values and standard deviation of the inside temperature of POM-02 (Tsukuba) (blue line) and the temperature of the shortwave-infrared detector (red line) from December 2013 to December 2016.

$V(\lambda, \Theta)$ is composed of the single scattering and multiple scattering radiances.

Therefore, Eq. (25) can be expressed as follows:

$$
\begin{aligned}
R(\lambda, \Theta) & =\frac{V_{1}(\lambda, \Theta)}{V(\lambda, 0) m \Delta \Omega}+R_{\mathrm{m}}(\lambda, \Theta) \\
& =\tau \omega_{0} P(\cos \Theta)+R_{\mathrm{m}}(\lambda, \Theta),
\end{aligned}
$$

where $R_{\mathrm{m}}(\lambda, \Theta)$ is the contribution of multiple scattering.

In the SKYRAD package, given the initial value of the column particle volume size distribution $(\mathrm{d} V / \mathrm{d} \log r)$ and the complex refractive indexes, $\tau, P(\cos \Theta)$, and $\omega_{0}$, are calculated assuming the spherical homogeneous particle. On the basis of these single scattering properties, the multiple scattering term (second term on the right side) in Eq. (26) is evaluated, and the single scattering term (first term on the right side) in Eq. (26) can be obtained. The new $\mathrm{d} V / \mathrm{d} \log r$ is retrieved from the single scattering term in Eq. (26) by the inversion scheme. Using the retrieved $\mathrm{d} V / \mathrm{d} \log r, \tau, P(\cos \Theta)$, and $\omega_{0}$ are calculated, and the observed values are reconstructed, and then the error is calculated. Until the error satisfies the convergence condition, the above procedure is iterated. In the above procedure, the complex refractive indexes for each channel are fixed and the measurement data with a scattering angle of less than $30^{\circ}$ are used.

Once $m \tau$ is obtained, the calibration constants can be estimated from $\ln V_{0}=\ln V R^{2}+m \tau$. However, in the SKYRAD package, $\ln V_{0}$ is determined from $\ln V R^{2}=$ $\ln V_{0}-m \tau_{\text {sca }} / W_{0}$. Comparing this equation with Eq. (24), $W_{0}$ must be the single scattering albedo. The single scattering albedo is defined as the ratio of the scattering coefficient to the extinction coefficient. Therefore, the single scattering albedo must be a value between 0 and 1 . However, $W_{0}$ is frequently greater than 1 . Therefore, it is treated as a constant in the estimation of $\ln V_{0}$. To distinguish between $\omega_{0}$ and $W_{0}, W_{0}$ was used. The fitted error, number of measurements, 

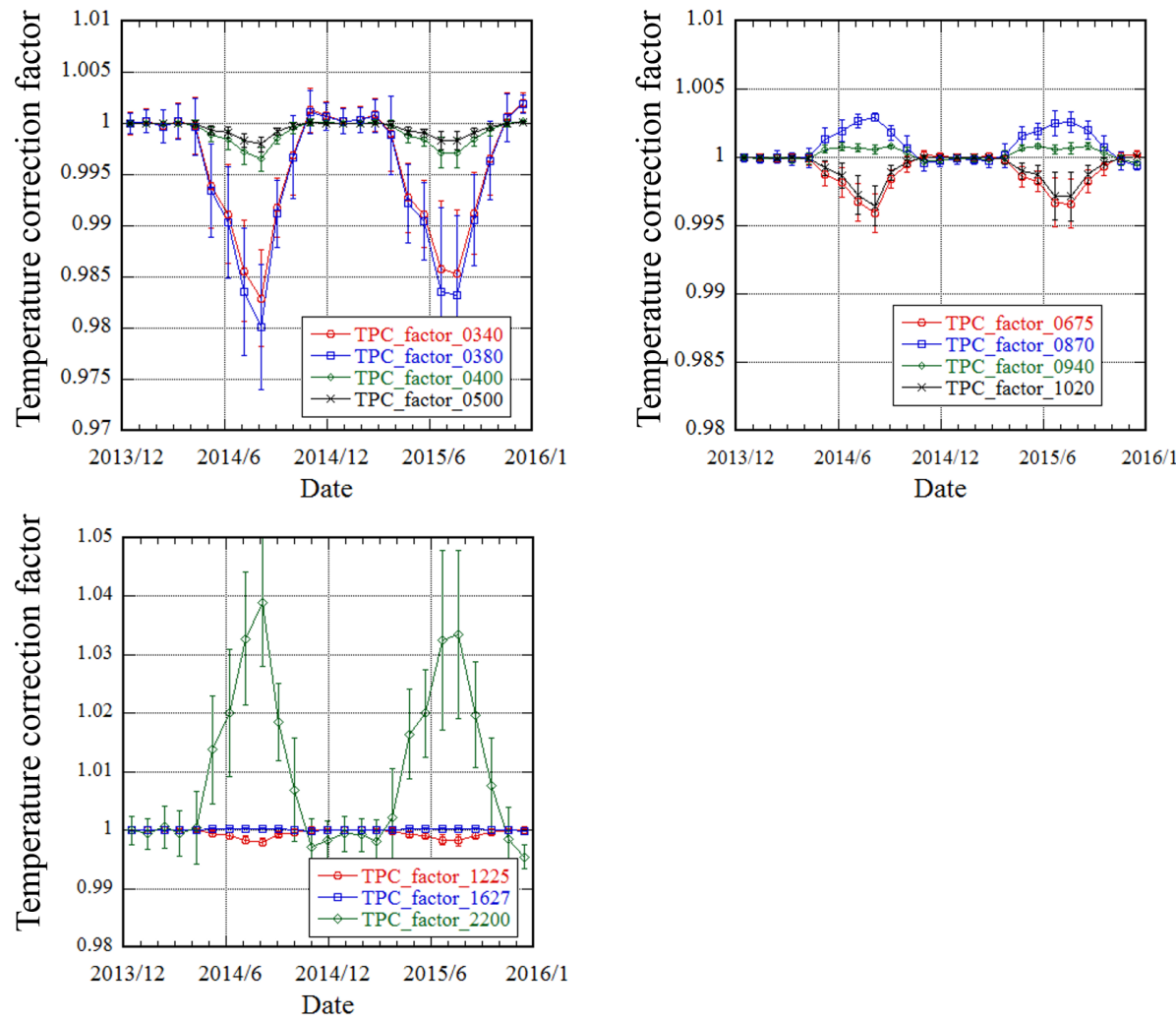

Figure 7. Monthly means of the temperature correction factors and standard deviation for POM-02 (Tsukuba) from December 2013 to December 2016.

and the transmittance are checked. Then, the data passing the check criterion are chosen as the calibration constants.

\subsection{Comparison between improved Langley and normal Langley method}

In the improved Langley (IML) method, the temperature dependence of the sensor output is not usually explicitly considered. This means that the calibration constant determined by the IML method implicitly includes the temperature dependence of the sensor output. Before comparing the calibration constant determined by the IML method and that transferred from POM-02 (calibration reference), we examined how much the sensor output changes with ambient temperature change.

In Fig. 6, the monthly mean values of the inside temperature of POM-02 (Tsukuba) and the temperature of the shortwave-infrared detector are shown. As seen from the figure, these temperatures were controlled in the period from November to April. In Fig. 7, the temperature correction factors are shown, where the reference temperature is $20^{\circ} \mathrm{C}$. In the summer, the sensor output must be corrected by $1.5 \%$ to $2 \%$ in the 340 and $380 \mathrm{~nm}$ channels and by $4 \%$ in the $2200 \mathrm{~nm}$ channel. In the other channels, the corrections were less than $0.5 \%$ : the temperature effect on these channels was small.
In Fig. 8, the calibration constants determined by the IML method from January 2014 to December 2015 are shown. To compare between the IML and normal Langley methods, the calibration constants interpolated from the calibration constants transferred from POM-02 (calibration reference) are also shown. The observations for the calibration transfer were conducted in December 2013, December 2014, and December 2015, and the calibration constants for POM02 (Tsukuba) were determined. The calibration constants in other months were obtained by linear interpolation and the temperature correction factor was also taken into consideration. In Fig. 8, the running means of the monthly IML values are also shown.

For every channel, the calibration constants determined by the IML method have a seasonal variation: they are larger in the winter and smaller in the summer. The amplitude of the seasonal variation is larger than that of the temperature correction factor. Furthermore, the annual trend of the calibration constant, after removing the seasonal variation, is almost the same as the normal Langley method. Furthermore, Fig. 8 shows much higher noise of the IML method compared with calibration transfer method.

In the $380 \mathrm{~nm}$ channel, the calibration constant changes due to the temperature dependence of the sensor output: in the summer the calibration constant decreases by about $2 \%$. 
(a) $340 \mathrm{~nm}$

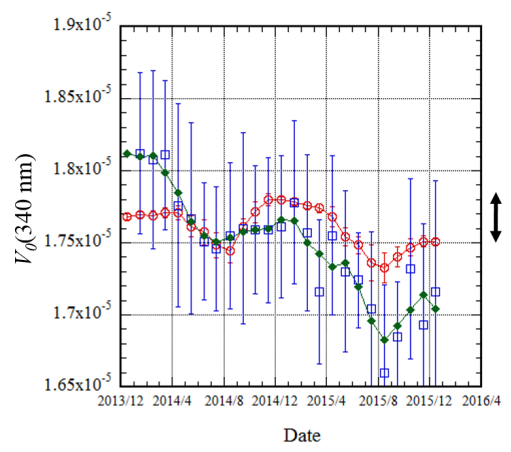

(c) $400 \mathrm{~nm}$

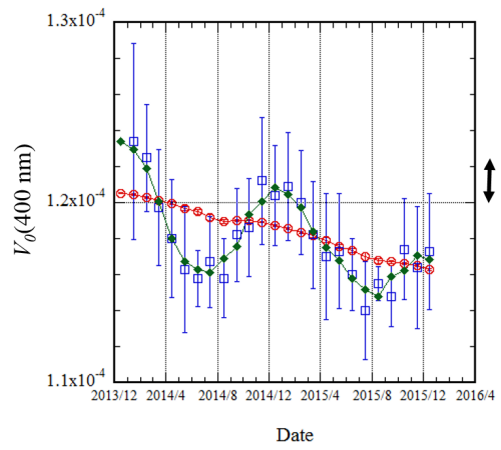

(e) $675 \mathrm{~nm}$

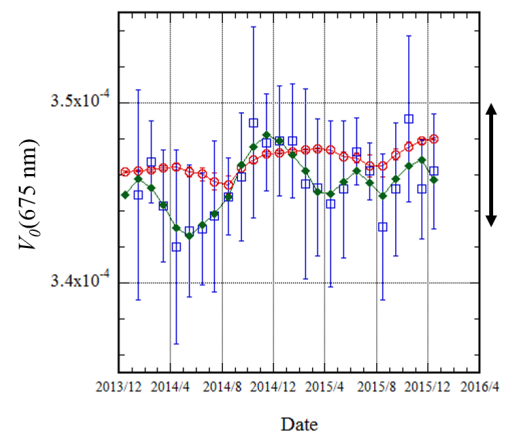

(g) $1020 \mathrm{~nm}$

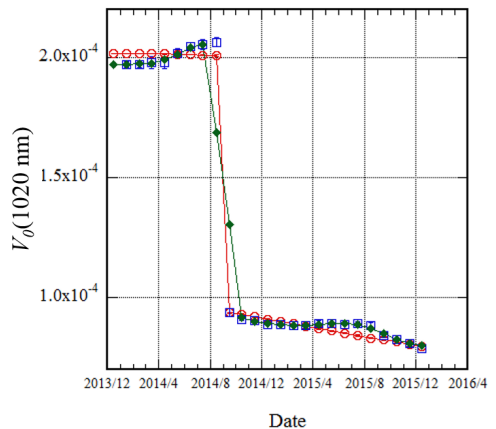

(b) $380 \mathrm{~nm}$

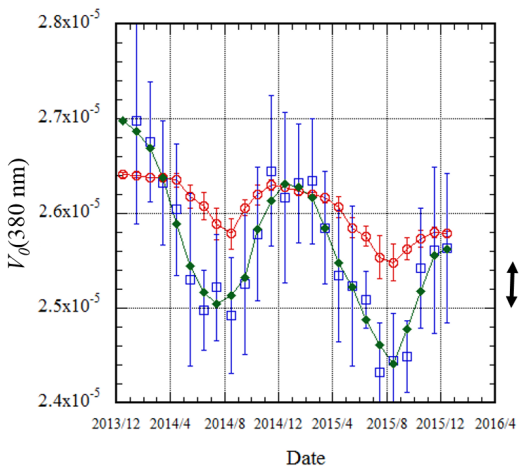

(d) $500 \mathrm{~nm}$

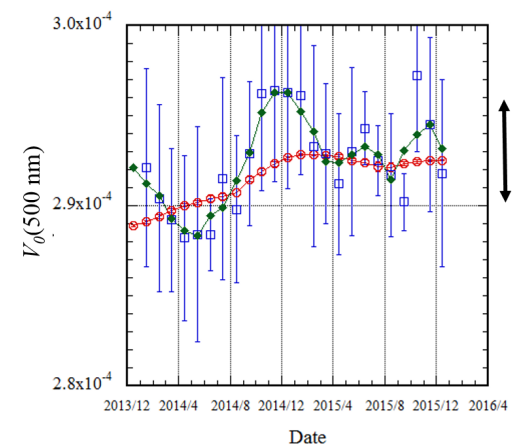

(f) $870 \mathrm{~nm}$

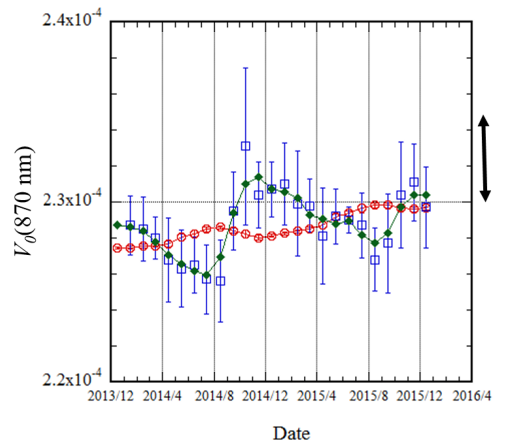

Figure 8. Time series of the calibration constant for POM-02 (Tsukuba) from January 2014 to December 2015. Blue open squares with error bars denote the calibration constants determined by the IML method. The green line shows the three-point running mean of IML, and the red line is the calibration constant interpolated from calibration constants transferred from POM-02 (calibration reference). The unit of $V_{0}$ is ampere (A). A double-headed arrow shows $2 \%$ width. A $2 \%$ scale arrow is not shown in the case of (g) $1020 \mathrm{~nm}$. 
Table 4. Statistics of the difference between IML method and normal Langley method.

\begin{tabular}{|c|c|c|c|c|c|c|c|}
\hline Wavelength (nm) & 340 & 380 & 400 & 500 & 675 & 870 & 1020 \\
\hline$V_{0}\left(\times 10^{-4}\right)$ & 0.17600 & 0.26022 & 1.1840 & 2.9161 & 3.4681 & 2.2863 & 1.2487 \\
\hline $\operatorname{BIAS}\left(\times 10^{-4}\right)$ & -0.00136 & -0.00428 & -0.0042 & 0.0083 & -0.0125 & 0.0017 & 0.0048 \\
\hline $\operatorname{rms}\left(\times 10^{-4}\right)$ & 0.00325 & 0.00649 & 0.0198 & 0.0225 & 0.0209 & 0.0197 & 0.0309 \\
\hline DFMAX $\left(\times 10^{-4}\right)$ & 0.00725 & 0.01218 & 0.0368 & 0.0475 & 0.0445 & 0.0489 & 0.0558 \\
\hline DFMIN $\left(\times 10^{-4}\right)$ & 0.00006 & 0.00059 & 0.0004 & 0.0011 & 0.0028 & 0.0002 & 0.0006 \\
\hline BIAS / $V_{0}$ & -0.0077 & -0.0164 & -0.0036 & 0.0028 & -0.0036 & 0.0008 & 0.0039 \\
\hline $\mathrm{rms} / V_{0}$ & 0.0184 & 0.0249 & 0.0167 & 0.0077 & 0.0060 & 0.0086 & 0.0247 \\
\hline DFMAX / $V_{0}$ & 0.0412 & 0.0468 & 0.0311 & 0.0163 & 0.0128 & 0.0214 & 0.0447 \\
\hline DFMIN/ $V_{0}$ & 0.0003 & 0.0023 & 0.0004 & 0.0004 & 0.0008 & 0.0001 & 0.0005 \\
\hline$V_{0 \_} 3 \mathrm{RM}\left(\times 10^{-4}\right)$ & 0.17604 & 0.26037 & 1.1848 & 2.9150 & 3.4678 & 2.2858 & 1.2794 \\
\hline $\operatorname{BIAS}\left(\times 10^{-4}\right)$ & -0.00114 & -0.00389 & -0.0030 & 0.0093 & -0.0124 & 0.0022 & 0.0030 \\
\hline $\operatorname{rms}\left(\times 10^{-4}\right)$ & 0.00303 & 0.00594 & 0.0178 & 0.0181 & 0.0171 & 0.0163 & 0.1014 \\
\hline DFMAX $\left(\times 10^{-4}\right)$ & 0.00495 & 0.01065 & 0.0321 & 0.0398 & 0.0352 & 0.0338 & 0.3663 \\
\hline DFMIN $\left(\times 10^{-4}\right)$ & 0.00022 & 0.00006 & 0.0007 & 0.0032 & 0.0013 & 0.0006 & 0.0004 \\
\hline BIAS / $V_{0 \_} 3 \mathrm{RM}$ & -0.0065 & -0.0149 & -0.0025 & 0.0032 & -0.0036 & 0.0010 & 0.0023 \\
\hline rms / $V_{0 \_} 3 \mathrm{RM}$ & 0.0172 & 0.0228 & 0.0150 & 0.0062 & 0.0049 & 0.0071 & 0.0793 \\
\hline 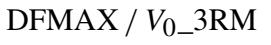 & 0.0281 & 0.0409 & 0.0271 & 0.0137 & 0.0102 & 0.0148 & 0.2863 \\
\hline DFMIN / $V_{0 \_3 R M}$ & 0.0013 & 0.0002 & 0.0006 & 0.0011 & 0.0004 & 0.0002 & 0.0003 \\
\hline
\end{tabular}

$V_{0}$ : mean calibration constant (IML method) from Jan. 2014 to Dec. 2015. $V_{0 \_}$3RM: mean calibration constant (IML method, three-point running mean) from Jan 2014 to Dec 2015. BIAS: bias (mean of differences between IML and normal Langley methods). rms: root mean squares of differences between IML and normal Langley methods. DFMAX: maximum difference between IML and normal Langley methods. DFMIN: minimum difference between IML and normal Langley methods.

The calibration constant $\left(V_{0}\right)$ determined by the IML method changes by up to $6 \%$. Even if the effect of the temperature change is subtracted from the seasonal variation, there is a difference of about $4 \%$ between the $V_{0}$ determined by the IML method and $V_{0}$ interpolated from $V_{0}$, determined by inter-comparison with the POM-02 (calibration reference). In the $400,500,675$, and $870 \mathrm{~nm}$ channels, there is a difference of $1 \%$ to $2 \%$ between the calibration coefficients, and in the $340 \mathrm{~nm}$ channel, there is a difference of $3 \%$ between the calibration coefficients. In the $1020 \mathrm{~nm}$ channel, as the interference filter was changed in September 2014, a direct comparison is difficult. In Table 4, the statistics of the difference between both calibration coefficients are shown. The RMSE is about $0.6 \%$ to $2.5 \%$, depending on the wavelength. This result is almost the same as in Campanelli et al. (2004). However, the maximum difference between both calibration coefficients was about $1.3 \%$ to $4.7 \%$, and these differences are rather large. The statistics of the three-point running mean for the IML method are also shown in Table 4. The errors are a bit smaller than those for the non-smoothed values: the RMSE is about $0.5 \%$ to $1.7 \%$.

Though the period of comparison is only 2 years, the calibration constant by the IML method represents the annual trend and implicitly includes the temperature dependence of the sensor output. However, the calibration constant has a seasonal variation of $1 \%$ to $3 \%$, and in some cases, the maximum difference reaches about $5 \%$. The $2 \%$ error in the calibration constant is not significant in a turbid atmosphere, but it is significant in a clear atmosphere, such as in polar and ocean regions. Furthermore, there is a possibility that the seasonal variation of the calibration constant causes an artificial seasonal variation in the retrieved parameters. The seasonal variation can be reduced by smoothing, such as with a running mean. However, over-smoothing dampens the temperature effect of the sensor output.

For the $500 \mathrm{~nm}$ channel, Fig. 9 shows a scatter plot of $\Delta V_{0}$ and the optical depth at $500 \mathrm{~nm}$, a scatter plot of $\Delta V_{0}$ and $W_{0}$, and a time series of $\Delta V_{0}$ from January 2014 to December 2015, where $\Delta V_{0}$ is the difference between $V_{0}$ determined by the IML method and $V_{0}$ interpolated from $V_{0}$ determined by inter-comparison with the POM-02 (calibration reference). In this case, the $V_{0}$ values determined by the IML method with errors less than 0.01 were chosen, where the error is the root mean square difference between the observations and the fitted line. As in Fig. 8, Fig. 9c shows that $\Delta V_{0}$ changes seasonally.

Figure 9a shows that there is a negative correlation between $\Delta V_{0}$ and the optical depth; the correlation coefficient is -0.31 . This result is consistent with the large amplitude of the seasonal change at short wavelengths. As a shorter wavelength usually corresponds to a thicker optical depth, a shorter wavelength corresponds to a larger amplitude of seasonal change of $V_{0}$ by the IML method.

In Tsukuba, the aerosol optical depth is thicker in the summer and thinner in the winter. Therefore, the seasonal change of $V_{0}$ by the IML method seems to be related to the optical 
(a)

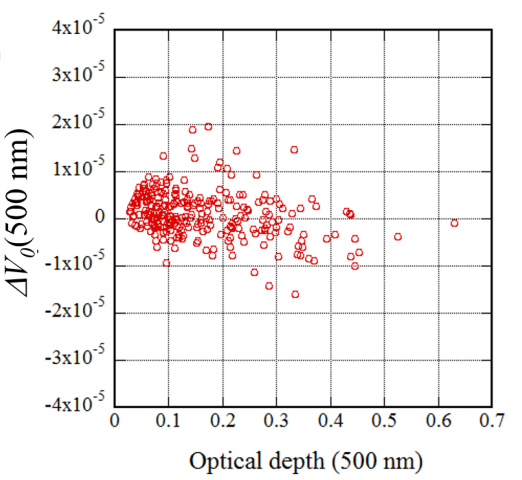

(c)

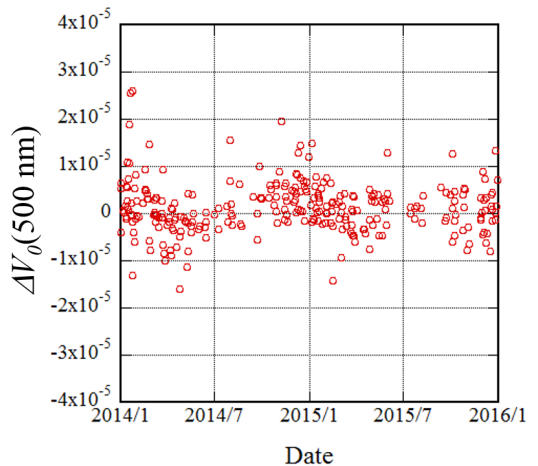

(b)

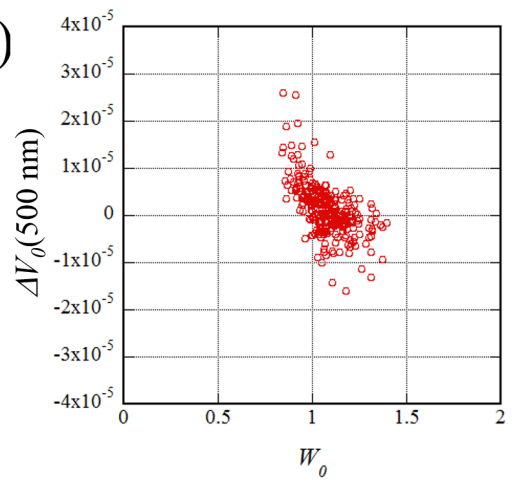

Figure 9. (a) Scatter plot of $\Delta V_{0}$ for the $500 \mathrm{~nm}$ channel and the optical depth at $500 \mathrm{~nm}$. (b) Scatter plot of $\Delta V_{0}$ and $W_{0}$ for the $500 \mathrm{~nm}$ channel. (c) Time series of $\Delta V_{0}$ for the $500 \mathrm{~nm}$ channel from January 2014 to December 2015. $\Delta V_{0}$ is the difference between $V_{0}$ determined by the IML method and $V_{0}$ interpolated from $V_{0}$, determined by inter-comparison with POM-02 (calibration reference). The unit of $V_{0}$ and $\Delta V_{0}$ is ampere $(\mathrm{A})$.

thickness. However, Fig. $9 \mathrm{~b}$ also shows that $\Delta V_{0}$ and $W_{0}$ are negatively correlated, specifically having a correlation coefficient of -0.59 , and that even if the correct $W_{0}$ is determined, the $\Delta V_{0}$ are scattered with a width of about $1.0 \times 10^{-5}$. As $W_{0}$ is a parameter related to the single scattering albedo or refractive index, this indicates that the error depends not only on the optical depth but also on the refractive index. There is a possibility that the seasonal variation of $V_{0}$ by the IML method may also be related to the seasonal variation of the refractive index.

In the current improved Langley method, the refractive index is fixed. We used $(1.5,-0.001)$ for all wavelengths as the initial value of the refractive index when using the SKYRAD package. However, this value may not be appropriate, and the further development of the method to determine $V_{0}$ while changing the refractive index is a topic for future work.

\section{Calibration using the calibrated light source}

In this section, the accuracy of the calibration using the calibrated integrating sphere is described. If POM- 02 can be calibrated using the calibrated light source, then POM-02 can be calibrated quickly without being influenced by the weather.

In this study, the integrating sphere, which is calibrated and maintained by the Japanese Aerospace Exploration
Agency (JAXA), was used (Yamamoto et al., 2002). This integrating sphere is used to calibrate the radiometers that are used to validate satellite remote sensing products.

To use the light source, the extraterrestrial solar irradiance, the SVA, and spectral response function of the sky radiometer are necessary, as well as the radiance emitted by the light source. The extraterrestrial solar irradiance by Gueymard (2004) was used here, along with the SVA obtained by processing the solar disk scan data.

When the integrating sphere is measured by POM- 02 , the sensor output is written as follows:

$$
V_{\mathrm{sph}}\left(\lambda_{0}\right)=\int_{\Delta \lambda} C(\lambda) \varphi(\lambda) I_{\mathrm{sph}}(\lambda) \mathrm{d} \lambda \cdot \Delta \Omega / \int_{\Delta \lambda} \varphi(\lambda) \mathrm{d} \lambda,
$$

where $V_{\mathrm{sph}}\left(\lambda_{0}\right)$ is the sensor output in channel $\lambda_{0}, C(\lambda)$ is the sensitivity at wavelength $\lambda, \varphi(\lambda)$ is the spectral response function of the interference filter, $I_{\mathrm{sph}}(\lambda)$ is the spectral radiance from the integrating sphere at wavelength $\lambda$, and the emitted radiance from the integrating sphere is assumed to be homogeneous. This equation is approximated as follows:

$V_{\mathrm{sph}}\left(\lambda_{0}\right) \cong C\left(\lambda_{0}\right) \bar{I}_{\mathrm{sph}}\left(\lambda_{0}\right) \cdot \Delta \Omega$,

where

$\bar{I}_{\mathrm{sph}}\left(\lambda_{0}\right)=\int_{\Delta \lambda} \varphi(\lambda) I_{\mathrm{sph}}(\lambda) \mathrm{d} \lambda / \int_{\Delta \lambda} \varphi(\lambda) \mathrm{d} \lambda$. 
Table 5. Calibration constants for POM-02 determined by using the calibrated integrating sphere measurement.

\begin{tabular}{|c|c|c|c|c|c|c|c|c|}
\hline $\begin{array}{l}\lambda_{0} \\
(\mathrm{~nm})\end{array}$ & $\begin{array}{r}\bar{F}_{0} \\
\left(\mathrm{~mW} \mathrm{~m}^{-2}\right. \\
\left.\mathrm{nm}^{-1}\right)\end{array}$ & $\begin{array}{r}\bar{I}_{\mathrm{sph}} \\
\left(\mathrm{mW} \mathrm{m}^{-2}\right. \\
\left.\mathrm{sr}^{-1} \mathrm{~nm}^{-1}\right)\end{array}$ & $\begin{array}{r}\Delta \Omega\left(\times 10^{-4}\right) \\
(\mathrm{sr})\end{array}$ & $\begin{array}{r}V_{\mathrm{sph}}\left(\times 10^{-10}\right) \\
\text { (A) }\end{array}$ & $\begin{array}{r}V_{\text {sun }}\left(\times 10^{-4}\right) \\
\text { (A) }\end{array}$ & $\begin{array}{r}V_{0}\left(\times 10^{-4}\right) \\
(\mathrm{A})\end{array}$ & $\begin{array}{r}\left(V_{\text {sun }}-V_{0}\right) / V_{0} \\
(\%)\end{array}$ & $I$ \\
\hline 340 & 1036.2 & - & 2.3970 & - & - & 0.19884 & - & - \\
\hline 380 & 1210.6 & 24.5 & 2.4370 & 1.9699 & 0.39941 & 0.39280 & 1.68 & $\operatorname{PTFE}(4.17 \mathrm{~A}(50 \mathrm{~W}) \times 4)$ \\
\hline 400 & 1523.3 & 49.6 & 2.4190 & 13.376 & 1.6982 & 1.6434 & 3.34 & $\operatorname{PTFE}(4.17 \mathrm{~A}(50 \mathrm{~W}) \times 4)$ \\
\hline 500 & 1964.6 & 238.1 & 2.4170 & 87.342 & 2.9817 & 2.7703 & 7.63 & $\operatorname{PTFE}(4.17 \mathrm{~A}(50 \mathrm{~W}) \times 4)$ \\
\hline 675 & 1496.5 & 764.1 & 2.4220 & 409.02 & 3.3075 & 3.2850 & 0.69 & $\operatorname{PTFE}(4.17 \mathrm{~A}(50 \mathrm{~W}) \times 4)$ \\
\hline 870 & 958.1 & 1171.1 & 2.4310 & 772.57 & 2.6000 & 2.4708 & 5.23 & $\operatorname{PTFE}(4.17 \mathrm{~A}(50 \mathrm{~W}) \times 4)$ \\
\hline 940 & 822.0 & 1218.8 & 2.4520 & 878.84 & 2.4173 & 2.3364 & 3.46 & $\operatorname{PTFE}(4.17 \mathrm{~A}(50 \mathrm{~W}) \times 4)$ \\
\hline 1020 & 698.1 & 1236.8 & 2.4520 & 682.48 & 1.5710 & 1.5559 & 0.97 & $\operatorname{PTFE}(4.17 \mathrm{~A}(50 \mathrm{~W}) \times 4)$ \\
\hline 1225 & 466.5 & 537.3 & 1.9800 & 204.73 & 0.89767 & 0.88715 & 1.19 & $\operatorname{PTFE}(3.30 \mathrm{~A}(50 \mathrm{~W}) \times 4)$ \\
\hline 1627 & 236.0 & 377.2 & 2.0000 & 459.62 & 1.4378 & 1.4456 & -0.54 & $\operatorname{PTFE}(3.30 \mathrm{~A}(50 \mathrm{~W}) \times 4)$ \\
\hline 2200 & 82.0 & 128.2 & 2.0570 & 237.19 & 0.73756 & 0.72472 & 1.77 & $\operatorname{PTFE}(3.30 \mathrm{~A}(50 \mathrm{~W}) \times 4)$ \\
\hline
\end{tabular}

$V_{0}$ : calibration constant through the normal Langley method

When the extraterrestrial solar irradiance is measured, the sensor output is written as follows:

$V_{\text {sun }}\left(\lambda_{0}\right)=\int_{\Delta \lambda} C(\lambda) \varphi(\lambda) F_{0}(\lambda) \mathrm{d} \lambda / \int_{\Delta \lambda} \varphi(\lambda) \mathrm{d} \lambda$,

where $V_{\text {sun }}\left(\lambda_{0}\right)$ is the sensor output in channel $\lambda_{0}$, and $F_{0}(\lambda)$ is the extraterrestrial solar spectral irradiance at $1 \mathrm{AU}$. This equation is approximated as follows:

$V_{\text {sun }}\left(\lambda_{0}\right) \cong C\left(\lambda_{0}\right) \bar{F}_{0}\left(\lambda_{0}\right)$,

where

$\bar{F}_{0}\left(\lambda_{0}\right)=\int_{\Delta \lambda} \varphi(\lambda) F_{0}(\lambda) \mathrm{d} \lambda / \int_{\Delta \lambda} \varphi(\lambda) \mathrm{d} \lambda$.

From Eqs. (28) and (31), $V_{\text {sun }}\left(\lambda_{0}\right)$ is written as follows:

$V_{\mathrm{sun}}\left(\lambda_{0}\right) \cong V_{\mathrm{sph}}\left(\lambda_{0}\right) \frac{\bar{F}_{0}\left(\lambda_{0}\right)}{\bar{I}_{\mathrm{sph}}\left(\lambda_{0}\right) \cdot \Delta \Omega}$

In Table 5, the calibration constants for POM-02 (calibration reference) determined from the integrating sphere measurement are compared with the results of the Langley method. At POM-02 (calibration reference), the relative difference was $0.7 \%$ to $7.6 \%$ in channels 2 to 8 (380 to $1020 \mathrm{~nm}$ ), and $0.5 \%$ to $1.8 \%$ in channels 9 to $11(1225,1627$, and $2200 \mathrm{~nm}$ ). The integrating sphere used in channels 2 to 8 is different from that in channels 9 to 11 .

The value of the extraterrestrial solar spectrum is dependent on the database. In Fig. 10, the following four data sets are shown: Thuillier et al., 2003; Gueymard, 2004; Chance and Kurucz, 2010; and the Wehrli Standard Extraterrestrial Solar Irradiance Spectrum (Wehrli, 1985; Neckel and Labs, 1981). The value is a mean value weighted by the response function of a triangle with full width at half maximum (FWHM) of $10 \mathrm{~nm}$. The ratios of the solar spectrum to Gueymard (2004) are also shown. These figures show that there are several percentage points of difference in the values depending on the wavelength. The SVA uncertainty is $1 \%$ (see Part 2, Uchiyama et al., 2018); the disk scan data were taken at MLO, where measurement conditions were good for the solar disk scan. The uncertainty of the integrating sphere was $1.7 \%$ (Yamamoto et al., 2002). Considering the magnitude of these errors, the above differences in the calibration constants seem reasonable. However, to reduce the optical depth error below 0.01 , a calibration coefficient error of several percent is too large. The calibration coefficient determined by the Langley method is better for estimating the optical depth from measurements of the direct solar irradiance. These issues were also pointed out by Shaw (1976) and Schmid and Wehrli (1995). The calibration using the standard lamp remains unchanged.

\section{Calibration of $940 \mathrm{~nm}$ channel}

The calibration constant depends on the extraterrestrial solar irradiance in the $940 \mathrm{~nm}$ band, the spectral response function of the interference filter, the spectral sensitivity of the detector, and the transmittance of radiometer optics. Calibration methods for the $940 \mathrm{~nm}$ channel, which is in the water vapor absorption band, have been considered extensively in previous studies (Reagan et al., 1987a, b, 1995; Bruegge et al., 1992; Thome et al., 1992, 1994; Michalsky et al., 1995, 2001; Schmid et al., 1996, 2001; Shiobara et al., 1996; Halthore et al., 1997; Cachorro et al., 1998; Plana-Fattori et al., 1998, 2004; Ingold et al., 2000; Kiedron et al., 2001, 2003). For example, Uchiyama et al. (2014) developed the Langley method, which takes into account the gas absorption, and the empirical relationship between the transmittance and precipitable water vapor (PWV) was determined from the theoretical calculation using the spectral response function and the model atmosphere. The PWV is estimated from the transmittance for the $940 \mathrm{~nm}$ channel. The empirical 

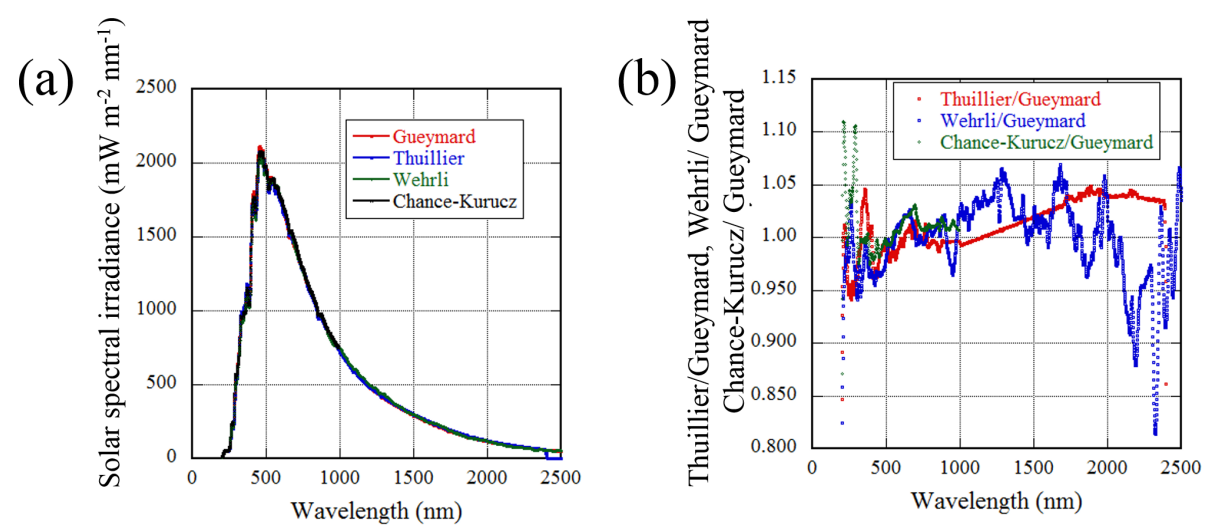

Figure 10. (a) Extraterrestrial solar spectra. The value is a mean value weighted by the response function of a triangle with FWHM of $10 \mathrm{~nm}$. The red line is Gueymard (2004), the blue line is Thuillier et al. (2003), the green line is Wehrli (1985), and black line is Chance and Kurucz (2010). (b) Ratios of the solar spectrum to Gueymard (2004).

formula is usually used for the transmittance of the $940 \mathrm{~nm}$ channel by water vapor.

Most POM-02 users have taken measurements without calibrating the $940 \mathrm{~nm}$ channel over a long time. To make use of these accumulated data, it is necessary to develop a calibration method using data at the observation site. Campanelli et al. (2014) developed a method to determine the calibration constant and parameters for the empirical formula of the transmittance using the on-site surface meteorological data and simultaneous POM-02 data. However, it is difficult to obtain the empirical formula for transmittance by the column water vapor from the surface measurement data.

In this study, given the spectral response function, the empirical transmittance formula is produced by the method shown in Uchiyama et al. (2014). Then, the modified Langley method shown below is performed using the empirical formula and the observation data.

The water vapor transmittance is approximated as follows:

$$
T_{\mathrm{r}}\left(\mathrm{H}_{2} \mathrm{O}\right)=\exp \left(-a(m \cdot \mathrm{pwv})^{b}\right)
$$

where $a$ and $b$ are fitting coefficients (see Appendix B), and pwv is PWV.

The sensor output $V$ is written as follows (Uchiyama et al., 2014):

$$
\begin{aligned}
V & =\frac{V_{0}}{R^{2}} \exp \left(-m\left(\tau_{\text {aer }}+\tau_{\mathrm{R}}\right)\right) T_{\mathrm{r}}\left(\mathrm{H}_{2} \mathrm{O}\right) \\
& =\frac{V_{0}}{R^{2}} \exp \left(-m\left(\tau_{\text {aer }}+\tau_{\mathrm{R}}\right)\right) \exp \left(-a(m \cdot \mathrm{pwv})^{b}\right),
\end{aligned}
$$

where $V_{0}$ is the calibration coefficient, $R$ is the distance between the earth and the sun, $\tau_{\text {aer }}$ is the aerosol optical depth at $940 \mathrm{~nm}$, and $\tau_{\mathrm{R}}$ is the optical depth of the molecular scattering (Rayleigh scattering). The aerosol optical depth $\tau_{\text {aer }}$ at $940 \mathrm{~nm}$ is interpolated from the optical depth at 870 and $1020 \mathrm{~nm}$. When interpolating $\tau_{\text {aer }}$ at $940 \mathrm{~nm}, \tau_{\text {aer }}$ was assumed to be proportional to $\lambda^{-\alpha}$, where $\lambda$ is the wavelength.
The above equation can be rewritten as follows:

$\ln V R^{2}+m\left(\tau_{\mathrm{aer}}+\tau_{\mathrm{R}}\right)=\ln V_{0}-a(\mathrm{pwv})^{b} m^{b}$.

The parameters on the left-hand side are known: $V$ is the measurement value, $R$ and $m$ can be calculated from the solar zenith angle, and $\tau_{\mathrm{R}}$ is estimated from the surface pressure. For example, $R$ can be calculated with the simplified formula in Nagasawa (1981), $m$ can be calculated as in Kasten and Young (1989), and $\tau_{\mathrm{R}}$ can be calculated as in Asano et al. (1983). In the case of POM-02, the sensor output is current, and the unit of the measurement value $V$ is ampere (A). If pwv is constant, then the right-hand side of the equation is a linear function of $m^{b}$. Therefore, the values on the lefthand side can be fitted by a linear function of $m^{b}$, and the intersection of the $y$ axis and the fitted line is $\ln V_{0}$.

Before the above-mentioned method was applied to the MRI data, it was first applied to the data taken at MLO, which has more stable weather conditions than Tsukuba. The results applied to the data taken at MLO in October and November 2014 and in October and November 2015 are shown in Table 6.

The calibration coefficients determined in 2014 and 2015 were $2.2973 \times 10^{-4} \mathrm{~A}\left(\mathrm{SD} / V_{0}=0.052\right)$ and $2.2954 \times$ $10^{-4} \mathrm{~A}\left(\mathrm{SD} / V_{0}=0.047\right)$, respectively.

The calibration coefficients determined by the Langley method with consideration of gas absorption in 2014 and 2015 were $2.3364 \times 10^{-4} \mathrm{~A}\left(\mathrm{SD} / V_{0}=0.093\right.$ and $2.3157 \times$ $10^{-4} \mathrm{~A}\left(\mathrm{SD} / V_{0}=0.097\right)$, respectively. Though the difference in the calibration coefficient between the Langley method with consideration of the gas absorption and the modified Langley method is $1.7 \%$ in 2014 and $0.9 \%$ in 2015, these calibration coefficients are very similar. The $\mathrm{CV}$ of the modified Langley method is smaller than the method that takes account of gas absorption more precisely than the modified Langley method. This may be due to errors in the estimates of the water vapor amount and distribution: the PWV is obtained from the GPS PWV, which has a low time resolu- 
Table 6. Calibration constant at $940 \mathrm{~nm}$ by the modified Langley method using the data taken at MLO.

\begin{tabular}{llrrr}
\hline & & & $\begin{array}{r}\text { Modified } \\
\text { Langley }\end{array}$ & Ratio \\
\hline \multirow{2}{*}{2014} & $V_{0}\left(\times 10^{-4}\right)$ & 2.3364 & 2.2973 & 0.9833 \\
& SD $\left(\times 10^{-4}\right)$ & 0.2183 & 0.1195 & \\
& SD $/ V_{0}$ & 0.0934 & 0.0520 & \\
& No. of data & 19 & 19 & \\
\hline \multirow{2}{*}{2015} & $V_{0}\left(\times 10^{-4}\right)$ & 2.3157 & 2.2954 & 0.9912 \\
& SD $\left(\times 10^{-4}\right)$ & 0.2236 & 0.1077 & \\
& SD $/ V_{0}$ & 0.0966 & 0.0469 & \\
& No. of data & 30 & 20 & \\
\hline
\end{tabular}

The data taken at MLO in 2014 and 2015 were used. $V_{0}$ : mean value; SD: standard deviation; ratio $=\left(\right.$ modified Langley $\left.V_{0}\right) /\left(\right.$ Langley $\left.V_{0}\right)$.

tion (30 min average), some data are missing, and the vertical distribution is estimated from only two radiosonde measurements per day near MLO.

The water vapor amount tends to fluctuate. Though the restriction that the PWV be constant is severe, the above method is applied to the data taken at Tsukuba, MRI and the calibration constants are compared with the calibration constant for POM-02 (calibration reference), which was calibrated by the Langley method, with consideration of the gas absorption, using the data taken at MLO and interpolated to the observation day (see Table 7).

The ratio of the calibration coefficients in the period of 14 December 2014 to 5 January 2015 ( 10 cases) was 1.0094 , and in the period of 1 to 30 December 2015 ( 17 cases) it was 0.99818. Thus, the difference between the two methods is less than $1 \%$.

Although it seems that the above-mentioned modified Langley method does not work well at all locations and under all weather conditions, the calibration constant of the $940 \mathrm{~nm}$ channel could be determined by applying the abovementioned method on a suitable stable and fine day at the observation site. We applied Langley method to data in the air mass range between 2 and 6 . Therefore, a stable interval of 1 to $2 \mathrm{~h}$ is necessary. The quality of the Langley plot can be checked by an analysis of the residuals; for acceptable data, no trend or systematic pattern is visible when the residuals vs. air mass are plotted. The $940 \mathrm{~nm}$ channels at many observation sites have not been calibrated and are not used. The application of the modified Langley method to the on-site observation data is the next best solution.

\section{Calibration coefficients of shortwave-infrared channels}

The measurements for the shortwave-infrared channels, 1225,1627 , and $2200 \mathrm{~nm}$, of POM-02 have been performed at many SKYNET sites, but the data have not been analyzed,
Table 7. Same as Table 6 but using the data taken at Tsukuba, MRI

\begin{tabular}{llrrr}
\hline & & & Modified \\
& & Langley & Rangley & Ratio \\
\hline \multirow{2}{2}{014} & $V_{0}\left(\times 10^{-4}\right)$ & 2.3343 & 2.3562 & 1.0094 \\
& $\mathrm{SD}\left(\times 10^{-4}\right)$ & 0.0002 & 0.1429 & \\
& $\mathrm{SD} / V_{0}$ & 0.0001 & 0.0598 & \\
& No. of data & 10 & 10 & \\
\hline \multirow{2}{*}{2015} & $V_{0}\left(\times 10^{-4}\right)$ & 2.3132 & 2.3090 & 0.9982 \\
& $\mathrm{SD}\left(\times 10^{-4}\right)$ & 0.0006 & 0.1043 & \\
& $\mathrm{SD} / V_{0}$ & 0.0003 & 0.0452 & \\
& No. of data & 17 & 17 & \\
\hline
\end{tabular}

The data taken at MRI, Tsukuba in December 2014 and December 2015 were used. $V_{0}$ : mean value; SD: standard deviation; ratio $=$ (modified Langley $\left.V_{0}\right) /\left(\right.$ Langley $\left.V_{0}\right)$.

because most POM-02 users cannot calibrate these channels by themselves.

These channels can be calibrated with the Langley method with a reasonable precision by taking into account the gas absorption. However, many users cannot make these measurements for the Langley method. Furthermore, the scattering of light in these channels is small and the IML method cannot be applied.

For some observation days, data with a very high correlation between channels may be obtained. In this case, when the calibration constant of one channel is known, then the calibration constants of the other channels can be inferred. The general method for the case when the ratio of the optical depths is constant was shown by Forgan (1994).

In this study, by assuming that the channels in the visible and near-infrared region including the $940 \mathrm{~nm}$ channel are calibrated, a similar method was applied to the shortwaveinfrared channels to determine the calibration constant and the precision was investigated.

The sensor output of POM-02 is written as follows:

$V=\frac{V_{0}}{R^{2}} \exp \left(-m\left(\tau_{\text {aer }}+\tau_{\mathrm{R}}\right)\right) T_{\mathrm{r}}($ gas $)$,

where $V$ is the sensor output, $V_{0}$ is the calibration constant, $R$ is the distance between the earth and the sun, $m$ is the air mass, $\tau_{\text {aer }}$ is the aerosol optical depth, $\tau_{\mathrm{R}}$ is the optical depth of the molecular scattering (Rayleigh scattering), and $T_{\mathrm{r}}$ (gas) is the transmittance of the gas absorption.

The sensor output for channels 1 and 2 are as follows:

$V_{1}=\frac{V_{01}}{R^{2}} \exp \left(-m\left(\tau_{1}+\tau_{\mathrm{R} 1}\right)\right) T_{\mathrm{r}_{1}}$ (gas),
$V_{2}=\frac{V_{02}}{R^{2}} \exp \left(-m\left(\tau_{2}+\tau_{\mathrm{R} 2}\right)\right) T_{\mathrm{r}_{2}}$ (gas).

The calibration constant of channel 1 is assumed to be known and that of channel 2 is determined. 
(a)

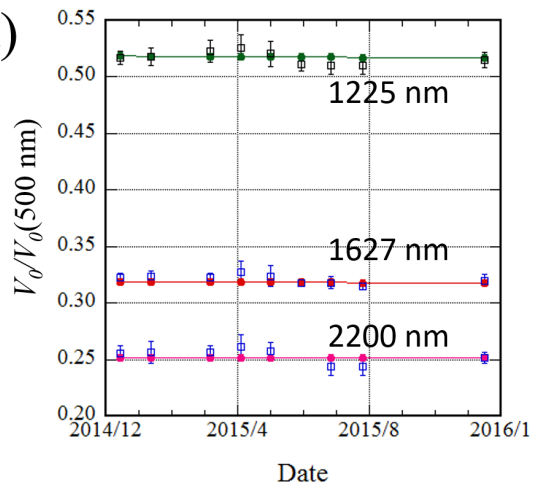

(b)

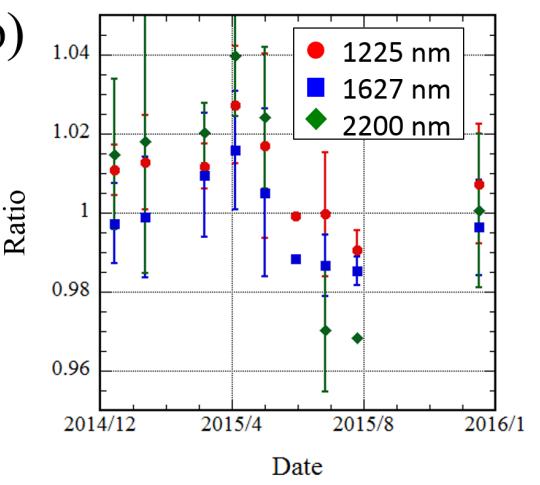

Figure 11. (a) Monthly mean of $V_{02} / V_{01}$ and the standard deviation: $V_{01}=V_{0}(500 \mathrm{~nm})$. (b) Ratio of $V_{02}$ to the interpolated value of the calibration constant determined by the Langley method. The red symbols are $1225 \mathrm{~nm}$, blue are $1627 \mathrm{~nm}$, and green are $2200 \mathrm{~nm}$.

From Eqs. (38) and (39), the following equation is obtained:

$$
\frac{V_{2}}{V_{1}}=\frac{V_{02} \exp \left(-m\left(\tau_{2}+\tau_{\mathrm{R} 2}\right)\right) T_{\mathrm{r}_{2}}(\mathrm{gas})}{V_{01} \exp \left(-m\left(\tau_{1}+\tau_{\mathrm{R} 1}\right)\right) T_{\mathrm{r}_{1}}(\mathrm{gas})}
$$

Therefore,

$$
\begin{aligned}
& \ln \frac{V_{2}}{V_{1}}+m\left(\tau_{\mathrm{R} 2}-\tau_{\mathrm{R} 1}\right)-\ln \frac{T_{\mathrm{r}_{2}} \text { (gas) }}{T_{\mathrm{r}_{1}}(\mathrm{gas})} \\
& =\ln \frac{V_{02}}{V_{01}}-m\left(\tau_{2}-\tau_{1}\right) \\
& =\ln \frac{V_{02}}{V_{01}}-\left(\frac{\tau_{2}}{\tau_{1}}-1\right) \tau_{1} m .
\end{aligned}
$$

If the water vapor amount is estimated from the $940 \mathrm{~nm}$ channel, and the mixing ratio of $\mathrm{CO}_{2}$ and $\mathrm{CO}$ is given, then the transmittance of gas can be estimated. Given the observation time and the latitude and longitude of the observation site, the air mass is calculated, and $\tau_{\mathrm{R} 1}$ and $\tau_{\mathrm{R} 2}$ are calculated from the surface pressure. Therefore, the left-hand side of Eq. (41) is known. Furthermore, when the ratio of the optical depth $\tau_{2} / \tau_{1}$ is constant, then this equation is a linear function of $m \tau_{1}$. Therefore, the intersection of the $y$ axis and the linearly fitted line is $\ln V_{02} / V_{01}$, and if $V_{01}$ is known, then $V_{02}$ is also known. Although this condition is not always satisfied, sometimes a linear fit will provide sufficient accuracy.

This method was applied to the data of POM-02 (calibration reference) from December 2014 to December 2015. The $500 \mathrm{~nm}$ was chosen as channel 1 in Eq. (41). The data used here had an RMSE of 0.005. In Fig. 11a, the monthly mean of $V_{02} / V_{01}$ and the standard deviation are shown. The lines of the ratio, which are interpolated from the calibration constant determined using the data taken in October and November of 2014 and 2015 at MLO, are also shown. In Fig. 11b, the ratio of the calibration constant by the above method and the interpolated value of the calibration constant determined from MLO data are shown. In the $1627 \mathrm{~nm}$ channel, the differences are less than $2 \%$ throughout the year and the differences in December and January are less than $1 \%$. In the $1225 \mathrm{~nm}$ channel, the differences are less than $2 \%$ except in April 2015. In the $2200 \mathrm{~nm}$ channel, the differences in some months are more than $3 \%$. However, in December 2015 , the differences in all channels are less than $1 \%, 0.8 \%$, $0.4 \%$, and $0.1 \%$, respectively. This shows that the difference between the calibration constant determined by the method shown here and that determined by the Langley method is less than $1 \%$ under suitable conditions. Currently, there is no method to calibrate the shortwave-infrared channel from on-site observation data. The method shown here is the next best solution.

\section{Summary and conclusion}

Atmospheric aerosols are an important constituent of the atmosphere. Measurement networks covering an extensive area from ground and space have been developed to determine the spatiotemporal distribution of aerosols. SKYNET is a ground-based monitoring system using sky radiometers POM-01 and POM-02, manufactured by Prede Co. Ltd., Japan. To improve their measurement precision, it is important to know the characteristics of the instruments and precisely calibrate them accordingly.

There are two constants that we must determine to make accurate measurements. One is the calibration constant, and the other is the SVA of the radiometer. The calibration constant is the output of the radiometer to the extraterrestrial solar irradiance at the mean earth-sun distance (1 AU) at the reference temperature. Additionally, the temperature dependence of the sensor output is another important characteristic.

In this study, the data obtained by two sky radiometers POM-02 of the JMA/MRI are considered. One of the sky radiometers is used as a calibration reference, and the other is used for continuous measurement at the Tsukuba MRI observation site.

The sensor output of POM-02 is dependent on the environmental temperature. The temperature dependence of the sensor output in the 340,380 , and $2200 \mathrm{~nm}$ channels was 
larger than in other channels. For example, the sensor output in the 340 and $380 \mathrm{~nm}$ channels of POM-02 (Tsukuba) increased at a rate of about $1.5 \%$ per $10^{\circ} \mathrm{C}$, and that in the $2200 \mathrm{~nm}$ channel increased at a rate of about $3 \%$ per $10^{\circ} \mathrm{C}$. In the other channels, the sensor output increased at a rate of less than $1 \%$ when the sensor's internal temperature was 0 to $40{ }^{\circ} \mathrm{C}$. The temperature dependence of the two POM-02 examined here was different for each instrument. If we want to make accurate measurements, we need to measure the temperature dependence for each instrument or use the channels with small temperature dependences.

For the measurement at Tsukuba, the temperature inside the POM-02 (Tsukuba) was controlled during the winter and spring seasons from November to April, but was not regulated, and thus was high during the summer. In the summer, sensor output must be corrected by $1.5 \%$ to $2 \%$ in the 340 and $380 \mathrm{~nm}$ channels and by $4 \%$ in the $2200 \mathrm{~nm}$ channel. In the other channels, the corrections were less than $0.5 \%$.

As well as determining the precision of the IML method, this study investigated the precision of the normal Langley method (i.e., the same air mass of air molecule scattering for all attenuating substances) and of the calibration transfer. From the data taken at MLO, the CV in the calibration constants determined by the normal Langley method $\left(\mathrm{SD} / V_{0}\right)$ was $0.2 \%$ to $1.3 \%$, except in the $940 \mathrm{~nm}$ channel. The effect of gas absorption was more than $10 \%$ in the $940 \mathrm{~nm}$ channel, but was less than $0.4 \%$ in the 1225 and $1627 \mathrm{~nm}$ channels and less than $1 \%$ in the $2200 \mathrm{~nm}$ channel, which all have weak gas absorption.

The comparison measurements for transferring the calibration constant were conducted in December at Tsukuba over about 10 days. The $\mathrm{CV}\left(\mathrm{SD} / V_{0}\right)$ for the transfer method was $0.1 \%$ to $0.5 \%$, depending on the wavelength. Though the measurements for the comparison depend on the weather conditions, when there are calibrated instruments it is a straightforward and accurate way to determine the calibration constant.

The long-term changes in the calibration constants $\left(V_{0}\right)$ for POM-02 (calibration reference) were also investigated. Roughly speaking, the degradation in the shorter wavelengths was larger than that in the longer wavelengths in the $\mathrm{Si}$ photodiode region. The changes in the $340 \mathrm{~nm}$ channel were $-10 \%$ per year from 2006 to 2012 . After replacing the lens in 2013, the degradation of the 340 and $380 \mathrm{~nm}$ channels became smaller. The manufacturer of the sky radiometer may have upgraded the lens. The change in the shortwave-infrared region (thermoelectrically cooled InGaAs photodiode) was less than $1 \%$ from 2009 to 2016 . These results indicate that calibration of the instruments is necessary at least once a year to monitor the degradation of $V_{0}$.

The calibration constant determined by the IML method and that transferred from the POM-02 (calibration reference) were compared using the data taken at Tsukuba from December 2013 to December 2015.
For every channel, the calibration constants determined by the IML method had a seasonal variation of $1 \%$ to $3 \%$. The calibration constants determined by the IML method implicitly include the temperature dependence of the sensor output. However, even if the change due to the temperature variation is subtracted from the seasonal variation, there is a difference of $1 \%$ to $4 \%$ between the two calibration coefficients. The RMSEs of the differences between the two calibration coefficients were about $0.6 \%$ to $2.5 \%$; this result is almost the same as that of Campanelli et al. (2004). However, in some cases, the maximum difference reached up to $5 \%$. Furthermore, the annual trend of the calibration constant excluding the seasonal variation was almost the same as for the normal Langley method. Furthermore, the calibration constants determined by the IML method had much higher noise than those transferred from the reference.

In order to investigate the error characteristics of the IML method, the relationship between $\Delta V_{0}$ and the optical depth and the relationship between $\Delta V_{0}$ and $W_{0}$ were investigated. $\Delta V_{0}$ is the difference between $V_{0}$ determined by the IML method and $V_{0}$ interpolated from $V_{0}$ determined by inter-comparison with the reference POM-02. As a result, it was found that $\Delta V_{0}$ and the optical depth were correlated. In Tsukuba, the aerosol optical depth changes seasonally. Therefore, the seasonal change of $V_{0}$ by the IML method seems to be related to the optical depth. Furthermore, $\Delta V_{0}$ and $W_{0}$, which are related to single scattering albedo or refractive index, were also correlated. In the current IML method, the refractive index is fixed. It is necessary to develop the proposed method to determine $V_{0}$ while changing the refractive index in the future.

We also tried to determine $V_{0}$ using the calibrated integrating sphere as the light source. The relative differences of $V_{0}$ were about $1 \%$ to $8 \%$ depending on the wavelength. Considering the magnitude of the errors in the extraterrestrial solar spectrum, SVA, and the integrating sphere, the above differences in the calibration constants seem reasonable. However, to reduce the optical depth error below 0.01 , an error of several percent in the calibration coefficient is too large.

The calibration method for water vapor in the $940 \mathrm{~nm}$ channel was considered using the on-site measurement data. $V_{0}$ was determined by the modified Langley method using a pre-determined empirical transmittance equation. The differences in the calibration coefficients between the normal Langley method and the modified Langley method were less than $1 \%$ on suitable stable and fine days.

The calibration method for the shortwave-infrared 1225 , 1627 , and $2200 \mathrm{~nm}$ channels was also considered using the on-site measurement data. It is assumed that channels in the visible and near-infrared wavelength region and the $940 \mathrm{~nm}$ channel are calibrated. Then, when the ratio of the optical depths between two channels is constant, the logarithm of the ratio of the sensor output can be written as a linear function of the air mass. Here, the calibration constant for one of the two channels is known and the transmittance of water va- 
por is calculated using the PWV estimated from the $940 \mathrm{~nm}$ channel. By fitting the logarithm of the ratio of sensor output to a linear function of the air mass, the ratio of the calibration constants is determined. By this method, the calibration constants could be determined within a $1 \%$ difference from the value by the Langley method on suitable days with good weather conditions.

In this study, it is shown that some channels have a nonnegligible temperature dependence in the sensor output and that the calibration constants determined by the IML method showed a seasonal variation. In channel $2(380 \mathrm{~nm})$, the max- imum error reached about $5 \%$. Reducing the uncertainty of the IML method is a task for future work, along with the problems related to the determination of calibration constants. In particular, the calibration constants for the $940 \mathrm{~nm}$ channel and the shortwave-infrared channels must be determined using on-site measurement data.

Data availability. Data used in this study are available from the corresponding author. 


\section{Appendix A: Weighted mean of calibration constant}

Let $\sigma$ be the uncertainty of $V_{0}$.

$$
\begin{aligned}
\ln \left(V_{0} \pm \sigma\right) & =\ln V_{0}\left(1 \pm \frac{\sigma}{V_{0}}\right) \\
& =\ln V_{0}+\ln \left(1 \pm \frac{\sigma}{V_{0}}\right) \\
& \simeq \ln V_{0} \pm \frac{\sigma}{V_{0}}
\end{aligned}
$$

where $\sigma / V_{0} \ll 1$.

Therefore, the uncertainty of $\ln V_{0}$ is $\sigma / V_{0}$.

Let us use the root mean square $\left(=\sigma_{\mathrm{L}}\right)$ of the residual from the linear regression line of the Langley plot as the uncertainty of $\ln V_{0}$.

$\sigma_{\mathrm{L}}=\frac{\sigma}{V_{0}}$

Therefore, the uncertainty of $V_{0}$ is $\sigma=\sigma_{\mathrm{L}} V_{0}$.

The weighted mean and standard deviation of $V_{0}$ were calculated by weighting $1 / \sigma^{2}=1 /\left(\sigma_{\mathrm{L}} V_{0}\right)^{2}$.

\section{Appendix B: Coefficients of water vapor transmittance}

Details of the method for determining the coefficients $a$ and $b$ are described in Uchiyama et al. (2014). The coefficients $a$ and $b$ depend on the vertical structure of the atmospheric temperature and humidity. Therefore, it is difficult to choose suitable values that can be applied under all atmospheric conditions. The range of variability of transmittance for an atmospheric profile is limited. Atmospheric transmittance is computed for a broad range of atmospheric conditions, and values for $a$ and $b$ were chosen that best fit the ensemble conditions.

The value of coefficients determined by our method for POM-02 (calibration reference) are $a=0.139186$ and $b=$ 0.631 . The values of the coefficients for the trapezoidal spectral response function, which has full width at a half maximum of $10 \mathrm{~nm}$ and central wavelength of $940 \mathrm{~nm}$, are $a=$ 0.147101 and $b=0.625$. 
Author contributions. This study was designed by AU and TM. The measurements of the sky radiometer were conducted by $\mathrm{AU}$ and $\mathrm{AK}$. The analyses were performed by AU and AK. The manuscript was written by $\mathrm{AU}$, and all authors contributed to editing and revision.

Competing interests. The authors declare that they have no conflict of interest.

Special issue statement. This article is part of the special issue "SKYNET - the international network for aerosol, clouds, and solar radiation studies and their applications (AMT/ACP inter-journal SI)". It is not associated with a conference.

Acknowledgements. This work was supported by the NIES GOSAT-2 project, Japan. This work was partially supported by JSPS KAKENHI, grant no. JP17K00531. The authors would like to thank Bruce Forgan and two anonymous reviewers for their useful comments.

Edited by: Omar Torres

Reviewed by: two anonymous referees

\section{References}

Asano, S., Murai, K., and Yamauchi, T.: An improvement of the computation method of the atmospheric turbidity factors, J. Meteorol. Res., 35, 135-144, 1983 (in Japanese).

Bruegge, C. J., Conel, J. E., Green, R. O., Margolis, J. S., Holm, R. G., and Toon, G.: Water vapor column abundance retrievals during FIFE, J. Geophys. Res., 97, 18759-18768, 1992.

Cachorro, V. E., Utrillas, P., Vergaz, R., Duran, P., de Frutos, A. M., and Martinez-Lozano, J. A.: Determination of the atmosphericwater-vapor content in the 940-nm absorption band by use of moderate spectral-resolution measurements of direct solar irradiance, Appl. Opt., 37, 4678-4689, 1998.

Campanelli, M., Nakajima, T., and Olivieri, B.: Determination of the solar calibration constant for a sun-sky radiometer: proposal of an in-situ procedure, Appl. Opt., 43, 651-659, 2004.

Campanelli, M., Nakajima, T., Khatri, P., Takamura, T., Uchiyama, A., Estelles, V., Liberti, G. L., and Malvestuto, V.: Retrieval of characteristic parameters for water vapour transmittance in the development of ground-based sun-sky radiometric measurements of columnar water vapour, Atmos. Meas. Tech., 7, 10751087, https://doi.org/10.5194/amt-7-1075-2014, 2014.

Chance, K. and Kurucz, R. L.: An improved high-resolution solar reference spectrum for earth's atmosphere measurements in the ultraviolet, visible, and near infrared, J. Quant. Spectrosc. Ra., 111, 1289-1295, 2010.

Dockery, D. W., Pope, C. A., Xu, X., Spengler, J. D., Ware, J. H., Fay, M. E., Ferris Jr., B. G., and Speizer, F. E.: An Association between Air Pollution and Mortality in Six U.S. Cities, New Engl. J. Med., 329, 1753-1759, 1993.
Dutton, E. G., Reddy, P., Ryan, S., and DeLuisi, J.: Features and Effects of Aerosol Optical Depth Observed at Mauna Loa, Hawaii: 1982-1992, J. Geophys. Res. 99, 8295-8306, 1994.

Forgan, B. W.: General method for calibrating Sun photometers, Appl. Opt., 33, 4841-4850, 1994.

Gueymard, C. A.: The sun's total and spectral irradiance for solar energy applications and solar radiation models, Sol. Energy, 76, 423-453, 2004.

Guzzi, R., Maracci, G. C., Rizzi, R., and Siccardi, A.: Spectroradiometer for ground-based atmospheric measurements related to remote sensing in the visible from a satellite, Appl. Opt., 24, 2859-2864, 1985.

Halthore, R. N., Eck, T. F., Holben, B. N., and Markham, B. L.: Sun photometric measurements of atmospheric water vapor column abundance in the 940-nm band, J. Geophys. Res., 102, 43434352, https://doi.org/10.1029/96JD03247, 1997.

Holben, B. N., Eck, T. F., Slutsker, I., Tanré, D., Buis, J. P., Setzer, A., Vermote, E., Reagan, J. A., Kaufman, Y. J., Nakajima, T., Lavenu, F., Jankowiak, I., and Smirnov, A.: AERONET-A federated instrument network and data archive for aerosol characterization, Remote Sens. Environ., 66, 1-16, 1998.

Ingold, T., Schmid, B., Matzler, C., Demoulin, P., and Kampfer, N.: Modeled and empirical approaches for retrieving columnar water vapor from solar transmittance measurements in the $0.72,0.82$, and $0.94 \mu \mathrm{m}$ absorption bands, J. Geophys. Res., 105, 24327 24343, 2000.

Kasten, F. and Young, A. T.: Revised optical air mass tables and approximation formula, Appl. Opt., 28, 4735-4738, 1989.

Kazadzis, S., Kouremeti, N., Diémoz, H., Gröbner, J., Forgan, B. W., Campanelli, M., Estellés, V., Lantz, K., Michalsky, J., Carlund, T., Cuevas, E., Toledano, C., Becker, R., Nyeki, S., Kosmopoulos, P. G., Tatsiankou, V., Vuilleumier, L., Denn, F. M., Ohkawara, N., Ijima, O., Goloub, P., Raptis, P. I., Milner, M., Behrens, K., Barreto, A., Martucci, G., Hall, E., Wendell, J., Fabbri, B. E., and Wehrli, C.: Results from the Fourth WMO Filter Radiometer Comparison for aerosol optical depth measurements, Atmos. Chem. Phys., 18, 3185-3201, https://doi.org/10.5194/acp-18-3185-2018, 2018.

Kiedron, P., Michalsky, J., Schmid, B., Slater, D., Berndt, J., Harrison, L., Racette, P., Westwater, E., and Han, Y.: A robust retrieval of water vapor column in dry Arctic conditions using the rotating shadowband spectroradiometer, J. Geophys. Res., 106, 2400724016, 2001.

Kiedron, P., Berndt, J., Michalsky, J., and Harrison, L.: Column water vapor from diffuse irradiance, Geophys. Res. Lett., 30, 1565, https://doi.org/10.1029/2003GL016874, 2003.

Kahn, R. A, Gaitley, B. J., Martonchik, J. V., Diner, D. J., Crean, K. A., and Holben, B. N.: Multiangle Imaging Spectroradiometer (MISR) global aerosol optical depth validation based on 2 years of coincident Aerosol Robotic Network (AERONET) observations, J. Geophys. Res., 110, D10S04, https://doi.org/10.1029/2004JD004706, 2005.

Liou, K. N.: An Introduction to Atmospheric Radiation, 2nd edn., Academic Press, p. 579, 2002.

Lohmann, U. and Feichter, J.: Global indirect aerosol effects: a review, Atmos. Chem. Phys., 5, 715-737, https://doi.org/10.5194/acp-5-715-2005, 2005.

Mélin, F., Clerici, M., Zibordi, G., Holben, B. N., and Smirnov, A.: Validation of SeaWiFS and MODIS aerosol products with glob- 
ally distributed AERONET data, Remote Sens. Environ., 114, 230-250, 2010.

Michalsky, J. J., Liljegren, J. C., and Harrison, L. C.: A comparison of sun photometer derivations of total column water vapor and ozone to standard measures of same at the Southern Great Plains atmospheric radiation measurement site, J. Geophys. Res., 100, 25995-26003, 1995.

Michalsky, J. J., Min, Q., Kiedron, P. W., Slater, D. W., and Barnard, J. C.: A differential technique to retrieve column water vapor using sun radiometry, J. Geophys. Res., 106, 17433-17442, 2001.

Nakajima, T., Tonna, G., Rao, R., Kaufman, Y., and Holben, B.: Use of sky brightness measurements from ground for remote sensing of particulate polydispersions, Appl. Opt., 35, 2672-2686, 1996.

Nagasawa, K.: Tentai no ichi keisan (Position calculation of celestial bodies), Chjin Shokan, p. 239, 1981 (in Japanese).

Neckel, H. and Labs, D.: Improved Data of Solar Spectral Irradiance from 0.33 to $1.25 \mu \mathrm{m}$, Sol. Phys., 74, 231-249, https://doi.org/10.1007/BF00151293, 1981.

Perry, K. D., Cahill, T. A., Schnell, R. C., and Harris, J. M.: Long-range transport of anthropogenic aerosols to the National Oceanic and Atmospheric Administration baseline station at Mauna Loa Observatory, Hawaii, J. Geophys. Res., 104, 1852118533, 1999.

Plana-Fattori, A., Legrand, M., Tanre, D., Devaux, C., Vermeulen, A., and Dubuisson, P.: Estimating the atmospheric water vapor content from sun photometer measurements, J. Appl. Meteorol., 37, 790-804, 1998.

Plana-Fattori, A., Dubuisson, P., Fomin, B. A., and de Paula Correa, M.: Estimating the atmospheric water vapor content from multifilter rotating shadow-band radiometry at Sao Paulo, Brazil, Atmos. Res., 71, 171-192, 2004.

Ramanathan, V., Crutzen, P. J., Kiehl, J. T., and Rosenfeld, D.: Aerosols, Climate, and the Hydrological Cycle, Science, 294, 2119-2124, 2001.

Reagan, J. A., Thomason, L. W., Herman, B. M., and Palmer, J. M.: Assessment of atmospheric limitations on the determination of the solar spectral constant from ground-based spectroradiometer measurements, IEEE T. Geosci. Remote Sens., GE-24, 258-265, 1986.

Reagan, J. A., Thome, K., Herman, B., and Gall, R.: Water vapor measurements in the 0.94 micron absorption band-Calibration, measurements and data applications, Proc. Int. Geoscience and Remote Sensing '87 Symposium, 18-21 May 1987, Ann Arbor, Michigan, 63-67, 1987a.

Reagan, J. A., Pilewskie, P. A., Herman, B. M., and Ben-David, A.: Extrapolation of Earth-based solar irradiance measurements to exoatmospheric levels for broad-band and selected absorptionband observations, IEEE T. Geosci. Remote Sens., 25, 647-653, 1987b.

Reagan, J., Thome, K., Herman, B., Stone, R., DeLuisi, J., and Snider, J.: A comparison of columnar water vapor retrievals obtained with near-IR solar radiometer and microwave radiometer measurements, J. Appl. Meteorol., 34, 1384-1391, 1995.

Remer, L. A., Kaufman, Y. J., Tanré, D., Mattoo, S., Chu, D. A., Martins, J. V., Li, R.-R., Ichoku, C., Levy, R. C., Kleidman, R. G., Eck, F. F., Vermote, E., and Holben, B. N.: The MODIS Aerosol Algorithm, Products, and Validation, J. Atmos. Sci., 62, 947-973, 2005
Russell, P. B., Livingston, J. M., Dutton, E. G., Pueschel, R. F., Reagan, J. A., DeFoor, T. E., Box, M. A., Allen, D., Pilewskie, P., Herman, B. M., Kinne, S. A., and Hofmann, D. J.: Pinatubo and pre-Pinatubo optical depth spectra: Mauna Loa measurements, comparisons, inferred particle size distributions, radiative effects and relationships to lidar data, J. Geophys. Res., 98, 2296922985, 1993.

Schmid, B. and Wehrli, C.: Comparison of Sun photometer calibration by use of the Langley technique and the standard lamp, Appl. Opt., 34, 4500-4512, 1995.

Schmid, B., Thome, K. J., Demoulin, P., Peter, R., Matzler, C., and Sekler, J.: Comparison of modeled and empirical approaches for retrieving columnar water vapor from solar transmittance measurements in the 0.94- $\mu$ m region, J. Geophys. Res., 101, 93459358, 1996.

Schmid, B., Michalsky, J. J., Slater, D. W., Barnard, J. C., Halthore, R. N., Liljegren, J. C., Holben, B. N., Eck, T. F., Livingston, J. M., Russell, P. B., Ingold, T., and Slutsker, I.: Comparison of columnar water-vapor measurements from solar transmittance methods, Appl. Opt., 40, 1886-1896, 2001.

Shaw, G. E.: Error analysis of multiwavelength sun photometry, Pageoph., 114, 1-14, 1976.

Shaw, G. E.: Solar spectral irradiance and atmospheric transmission at Mauna Loa Observatory, Appl. Opt., 21, 2006-2011, 1982.

Shaw, G. E.: Sun photometry, B. Am. Meteorol. Soc., 64, 4-11, 1983.

Shiobara, M., Spinhirne, J. D., Uchiyama, A., and Asano, S.: Optical depth measurements of aerosol, cloud, and water vapor using sun photometers during FIRE Cirrus IFO II, J. Appl. Meteorol., 35, 36-46, 1996.

Takamura, T., Nakajima, T., and SKYNET community group: Overview of SKYNET and its Activities, Opt. Pura Aplicada, 37, 3303-3308, 2004.

Tanaka, M., Nakajima, T., and Shiobara, M.: Calibration of a sunphotometer by simultaneous measurements of direct-solar and circumsolar radiations, Appl., Opt., 25, 1170-1176, 1986.

Thomason, L. W., Herman, B. M., and Reagan, J. A.: The effect of atmospheric attenuators with structured vertical distributions on air mass determinations and Langley plot analyses, J. Atmos. Sci., 40, 1851-1854, 1983.

Thome, K., Herman, B. M., and Reagan, J. A.: Determination of precipitable water from solar transmission, J. Appl. Meteorol., 31, 157-165, 1992.

Thome, K. J., Smith, M. W., Palmer, J. M., and Reagan, J. A.: Threechannel solar radiometer for the determination of atmospheric columnar water vapor, Appl. Opt., 33, 5811-5819, 1994.

Thuillier, G., Hersé, M., Labs, D., Foujols, T., Peetermans, W., Gillotay, D., Simon, P. C., and Mandel, H.: The solar spectral irradiance from 200 to $2400 \mathrm{~nm}$ as measured by the SOLSPEC spectrometer from the ATLAS and EURECA missions, Sol. Phys., 214, 1-22, https://doi.org/10.1023/A:1024048429145, 2003.

Uchiyama, A., Yamazaki, A., and Kudo, R.: Column Water Vapor Retrievals from Sky-radiometer (POM-02) 940nm Data, J. Meteorol. Soc. Jpn., 92, 195-203, https://doi.org/10.2151/jmsj.2014A13, 2014.

Uchiyama, A., Matsunaga, T., and Yamazaki, A.: The instrument constant of sky radiometers (POM-02) - Part 2: 
Solid view angle, Atmos. Meas. Tech., 11, 5389-5402, https://doi.org/10.5194/amt-11-5389-2018, 2018.

Wehrli, C.: Extraterrestrial Solar Spectrum, Publication no. 615, Physikalisch-Meteorologisches Observatorium and World Radiation Center (PMO/WRC) Davos Dorf, Switzerland, July 1985.

Wehrli, C.: GAW-PFR: A network of Aerosol Optical Depth observations with Precision Filter Radiometers, in: WMO/GAW Experts workshop on a global surface based network for long term observations of column aerosol optical properties, Tech. rep., GAW Report No. 162, WMO TD No. 1287, 2005.

WMO: WMO/GAW Experts workshop on a global surface-based network for long term observations of column aerosol optical properties, GAW Report 162, WMO/TD-No 1287, Davos 2004, edited by: Baltensperger, U., Barries, L., and Wehrli, C., 2005.
World Health Organisation (WHO): Air quality guidelines for particulate matter, ozone, nitrogen dioxide and sulfur dioxide, Global update 2005, Summary of risk assessment, World Health Organization, Geneva, Switzerland, p. 22, 2006.

World Health Organization Regional Office for Europe: Review of Evidence on Health Aspects of Air Pollution-REVIHAAP Project, Technical Report WHO, Copenhagen, p. 298, 2013.

Yamamoto, Y., Arai, Y., and Sakuma, F.: Development of a calibration standard of the spectral radiance for optical sensors, SICE 2002, Proceedings of the 41st SICE Annual Conference, 3, 1885-1890, https://doi.org/10.1109/SICE.2002.1196613, 2002. 